\title{
STRATEGIC SIGNALING AND NEW TECHNOLOGICALLY SUPERIOR PRODUCT INTRODUCTION: A GAME-THEORETIC MODEL WITH SIMULATION
}

\author{
Madjid TAVANA ${ }^{1,2^{*}}$, Debora Di CAPRIO ${ }^{3}$, Francisco J. SANTOS-ARTEAGA ${ }^{4}$ \\ ${ }^{1}$ Business Systems and Analytics Department, Distinguished Chair of Business Analytics, \\ La Salle University, Philadelphia, PA 19141, USA \\ ${ }^{2}$ Business Information Systems Department, Faculty of Business Administration and Economics, \\ University of Paderborn, D-33098 Paderborn, Germany \\ ${ }^{3}$ Department of Mathematics and Statistics, York University, Toronto, M3J 1P3, Canada \\ ${ }^{4}$ Faculty of Economics and Management, Free University of Bolzano, Bolzano, Italy
}

Received 27 March 2017; accepted 12 September 2017

\begin{abstract}
User acceptance of technology is essential to determine its success. The current paper incorporates the main properties of the technology acceptance models (TAMs) developed by management scholars into a pre-commitment signaling duopolistic framework, where two competing firms must decide the level of technological improvement of the products being introduced. As a result, the corresponding equilibria of the duopolistic technological games will be determined by demand-based factors, providing a novel approach and complementing the current supply-based economic and operational research models developed in the literature. The proposed model will be simulated numerically to illustrate the strategic optimality of the update process of smartphone and tablet characteristics defined by Apple and Samsung as the market developed.
\end{abstract}

Keywords: game theory, simulations, product planning, information sharing, strategic signaling, technological improvement.

JEL Classification: O31, O32, D83, L15

\section{Introduction. Problem statement and contribution}

User acceptance of technology is essential to determine its success. This is particularly true when considering the introduction of new information technology (Dillon \& Morris, 1996; Phan \& Daim, 2011; Hameed, Counsell \& Swift, 2012). The management literature has concentrated on identifying and studying the main characteristics that influence users' adoption of a given technology. At the same time, operational researchers and economists have generally focused their respective models in a different direction from the technology acceptance

\footnotetext{
*Corresponding author. E-mail: tavana@lasalle.edu
} 
models (TAMs) developed by management scholars. This is despite the fact that the acceptance of new technology is not necessarily an immediate consequence of the introduction of technologically developed products (Geroski, 2000).

The main objective of this paper is to study the strategic behavior of firms when introducing technologically improved products in the market whose success and acceptance rely directly on the main behavioral characteristics of the potential consumers being targeted. In this regard, the main contributions of the paper can be summarized as follows:

- It incorporates the main properties of the TAMs developed by management scholars into a pre-commitment signaling duopolistic framework.

- It studies the role played by the information acquisition process and the preferences of decision makers (DMs) in the technological product improvement strategies of firms.

- It introduces a demand-based strategic equilibrium approach to the process of technological improvement of products and their diffusion. Depending on the number of categories considered and the subset of characteristics being improved the model illustrates the optimality of

a. Apple's leapfrogging strategy when introducing the iPod Nano before newcomers could pose a serious threat to the market developed by the iPod Mini, thereby creating and monopolizing its own technological niche market.

b. The product development process followed by Apple and Samsung when introducing sequential improvements in the operative systems of their smartphones and tablets while competing fiercely over their design and coolness characteristics of both products.

- It carries out numerical simulations to model the decision making process of both consumers and firms as the number of potential improvements on the products increases.

\section{Background and literature review}

\subsection{User acceptance of technological products and the rivalry between Apple and Samsung}

Technology adoption models, such as TAM (Davis, 1989) and several subsequent extensions like the Diffusion of Innovation Theory (Rogers, 2003), contain both utilitarian and hedonic characteristics. The effect that both types of characteristics have in the consumption patterns of smartphone users, with particular emphasis on Apple's iPhone, is illustrated by ArrudaFilhoa, Cabusasb \& Dholakiab (2010) and Arruda-Filhoa and Lennon (2011). In this regard, West and Mace (2007) provide a summarized history of the emergence of the smartphone niche market, concentrating on the iPhone case. The authors explain how Apple extended its iPhone strategy to the iPod market, through the iPodTouch, and introduced annual releases of updated models and operating system software for the iPhone. The operating system of the iPhone has been consistently improved through time, with iPhone users generating more traffic than its Android-based competitors, i.e. Samsung, within markets such as the German one (Gerpott, Thomas \& Weicher, 2013).

West and Mace (2007) outlined the key features emphasized by consumers when acquiring an iPhone, which comprised the device's design, display, and multi-touch interface. Given 
the capacity of competitors to mimic the haptic experience provided by the touch screen, consumers concentrated on coolness, a hedonic concept based on the design of the product, as the main characteristic on which to base the purchase of Apple products, see The Guardian (2012). As a matter of fact, similarities in product design have led to a relentless legal battle between the two main market competitors, Apple and Samsung (Gobble, 2012). For example, the coolness characteristic factor was capital in the ruling of Judge Colin Birss within one of the several copyright infringement trials involving Samsung and Apple. In this case, the ruling refers to the tablet market where the Samsung Galaxy tab and the iPad compete

"From the front they belong to the family which includes the Apple design; but the Samsung products are very thin, almost insubstantial members of that family with unusual details on the back. They do not have the same understated and extreme simplicity which is possessed by the Apple design. They are not as cool. The overall impression produced is different." The Guardian (2012).

Similarly, Cockrill (2012) illustrated how the key influencing variables determining the purchase of iPods were high functionality, reliability, and "cool" design of the products. In particular, iPod owners considered their MP3 players to be much "cooler" than did non-iPod owners.

Thus, Apple emphasized the coolness in the design of its products as a fundamental characteristic while introducing subsequent annual improvements in their operating system. This was particularly the case in the smartphone and tablet markets. Samsung followed a similar strategy, aiming at improving the design of its products, together with subsequent improvements in its [more compatible] Android-based operating system (Tseng, Liu \& Wu, 2014). The importance of the operating system as a competitive conditioning characteristic was emphasized by Kenney and Pon (2011). In this regard, the higher compatibility of Samsung's Android-based system was one of the main factors allowing its Galaxy series to take over the smartphone market.

\subsection{Fundamental requirements of the model}

The model designed to study the behavior of Apple and Samsung as the smartphone and tablet markets were being developed should account for the two main characteristic categories emphasized by both firms, namely the coolness in the design of their products together with the sequential evolution of their operating systems. Given the information acquisition and evaluation behavior of potential users, the model should allow us to assess whether the fierce competition in the design characteristic together with the subsequent sequential improvements in the respective operating systems constitute an optimal strategy for both firms. Moreover, the model should also allow us to answer the related question so as to the optimality of introducing improvements over already monopolized markets such as that of the iPod Mini.

A taxonomy of the adoption factors for smartphones containing utilitarian and hedonic characteristics is introduced in Figure 1. This figure expands Figure 5 in Aldhaban (2012) and adapts it to the formal environment of the current paper. Other taxonomies based on extensions derived from the TAM present similar classifications of the main adoption factors (Aldhaban, 2012). 


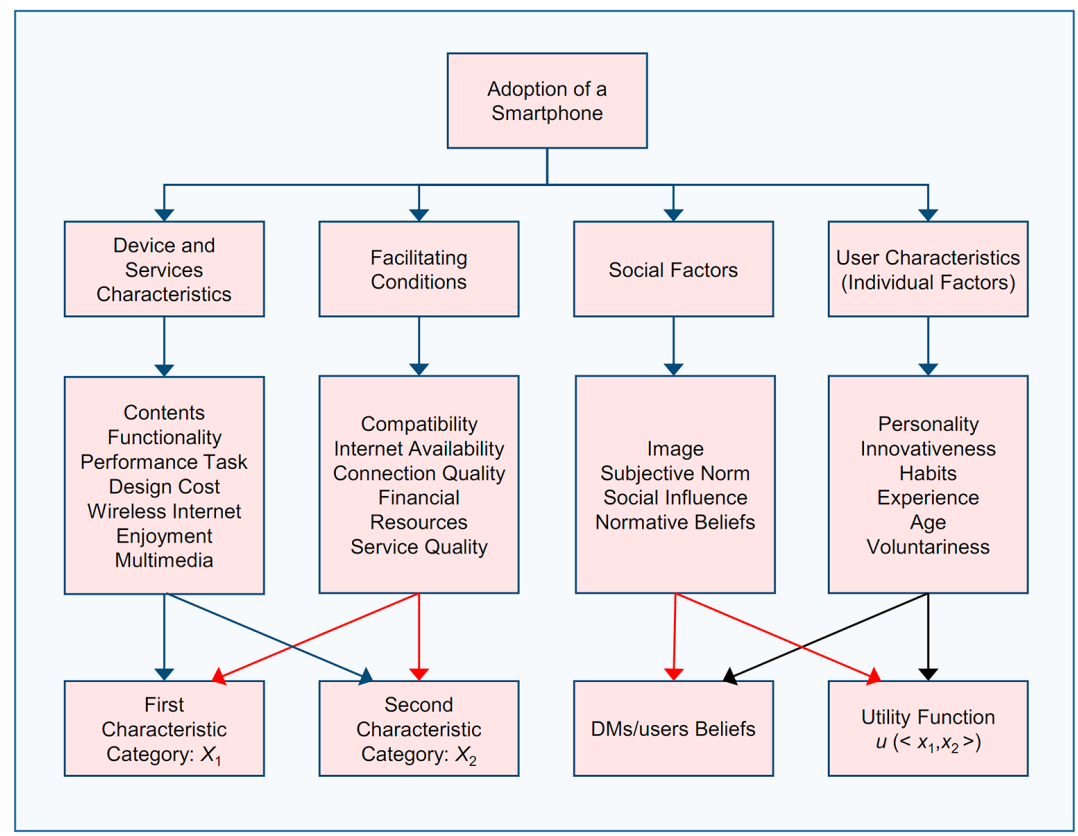

Figure 1. A taxonomy of the adoption factors for smartphones

Note that this taxonomy, which incorporates elements from the TAM and several of its extensions (Aldhaban, 2012), concentrates on product categories that may be classified in terms of design and performance together with those related to the operating system, its functionality and compatibility. Note also that most of the device and service characteristics are verifiable to some extent before the purchase takes place while the facilitating conditions require a deeper analysis of the product. DMs may include different characteristics within the first and second categories and compute a weighted average for each category. This can be done by applying standard aggregation techniques, such as Saaty's (1980) analytic hierarchy process, to a given group of characteristics within a category. The resulting weighted average values can be used to perform comparisons between products and determine the optimal information acquisition and choice behavior of DMs.

The factors defining DMs (users) may be assumed to be contained within their subjective probability densities [beliefs], regarding the potential values of the characteristic categories defining the product, and the utility functions with which they are endowed. The beliefs of the DMs constitute their perspective on the potential spread of the product characteristics and the resulting social factors determining its purchase.

To summarize, the model designed should account for the two characteristic categories defining the products as well as the different types of DMs that may be defined in terms of their risk attitudes and beliefs regarding the characteristics of the products. The inclusion of these elements in the resulting decision making structure should determine the optimal information acquisition and choice behavior of the DMs, which must be considered by both firms before deciding what characteristics to improve technologically and the intensity of the improvements. 


\subsection{Complementing and extending the technology diffusion literature}

The strategic decision model defined in the current paper encompasses and extends different branches of the technology diffusion literature, namely, the industrial organization one dealing with duopolistic competition settings, the operational research one on multi-criteria decision making (MCDM) and the management one following from the TAM. We complement these branches by incorporating their main features within a common strategic decision environment and expand them by adding a sequential information acquisition framework on the side of the DMs.

That is, game theoretical duopolistic environments tend to concentrate on the supply side of the market and do not account for the multiple characteristics of the products that must be observed and analyzed by the DMs (Tirole, 1988; Sutton, 1998). On the other hand, the MCDM and TAM literatures focus solely on the demand side of the market, leaving aside the strategic information transmission setting faced by the supply side and the fact that the DMs must acquire the information required to evaluate the different alternatives.

In particular, several MCDM methods have been applied to evaluate and rank technological products. This has been generally done without accounting for the strategic signaling behavior of firms when introducing these products in the market. Tsai and Chang (2013) evaluated the performance of Table PCs using four different MCDM tools and found that the design and function of a product are among the most important evaluation characteristics. Liao, Lin and Fu (2016) analyzed new product launch strategies as MCDM problems requiring the evaluation of different attributes. These authors integrated the analytic network process, the technique for order preference by similarity to an ideal solution (TOPSIS) and multi-choice goal programming. Similarly, Hsu, Tsai and Tzeng (2017) defined a hybrid multi-attribute decision making model based on the environmental attributes influencing digital convergence through an influential network relationship map. They concluded that the development of digital convergence and the reduction of performance-gaps may require considering both the strategic behavior of firms as well as the information assimilation capacity of the DMs.

A common conclusion derived from the recent MCDM literature is that firms should focus on product innovation in order to grow and retain loyal customers. However, as stated above, the economic literature does not generally assume firms to account for the different categories on which DMs focus when deciding what characteristics to improve while competing with a rival duopolist.

Consider now the empirical analyses performed on the technology commercialization capabilities of firms. Aggarwal, Gupta, Govindan, Jha and Meidute (2014) studied different diffusion models of technological consumer products in a segmented market under mass and differentiated promotional strategies. These authors accounted for dynamic variations of the potential market size and incorporated the repurchase behavior of adopters as a form of learning. Kim, Lee, Park and Oh (2011) examined the existing relationship among R\&D capabilities, such as learning and external networking, the commercialization of technology and the performance of innovations. They focused on Korean SMEs in IT-related businesses and found that the technology commercialization capabilities of firms mediate in the rela- 
tionship between R\&D intensity and innovation performance. Zemlickienè, Mačiulis and Tvaronavičienè (2017) identified the main factors determining the commercial potential of technologies through a statistical analysis of the expert opinions evaluating the significance of the different factors. Their analysis is particularly relevant if implemented as basic performance guidelines during the initial stages of the technology development process.

It should be noted that despite applying a commercialization perspective to the process of technology diffusion, the papers described above do not consider the information acquisition incentives of DMs when being presented with new or improved products. In this regard, Chen and Ann (2016) analyzed the satisfaction of Taiwanese customers with the main smartphone brands. They found that Samsung was the top performer when considering customer satisfaction, while Apple displayed the highest customer loyalty. They also validated a positive relationship between customer satisfaction and brand loyalty, an extension that can be easily implemented in the strategic environment introduced in the current paper (Tavana, Di Caprio \& Santos Arteaga, 2016b). Moreover, the perception of quality and other product attributes should have a direct effect on the beliefs and behavior of the DMs. For instance, Shin (2017) assessed quality from a user-centered perspective by examining the relationship between consumer experiences and their quality perception of the internet of things. From a formal perspective, an expected utility model constitutes a valid instrument to incorporate these behavioral facts within the information acquisition process of the DMs that must be considered by firms.

Similar conclusions apply to the most recent versions of the TAM, which allow for the inclusion of the effects of trust and perceived risk when adopting and using information technologies (ITs). These effects generally relate to managers and their capacity to make informed decisions so as to promote the acceptance and effective utilization of ITs among employees (Venkatesh \& Bala, 2008).

The TAM literature has currently focused on emphasizing the differences in the cognitions underlying the formation of behavioral intention and behavioral expectation and their respective effects on the adoption and use of ITs (Maruping, Bala, Venkatesh \& Brown, 2017). The empirical research performed in this area follows an approach similar to those of the decision making literature but without considering the information acquisition behavior of DMs. For example, Lin, Chao and Tang (2017) analyzed the behavioral intentions of those phone users who have not yet shifted to a smartphone. They found that the main factors determining the intention of non-smartphone users to either switch or resist to smartphones concentrate within consumer psychographics and smartphone characteristics. Swapana and Padmavathy (2017) used a sample of Indian university students to illustrate that social needs, social influence, convenience and brand name positively affect dependency on smartphones. Moreover, Marcondes Moraes (2016) conducted a survey to highlight the herd behavior observed in the adoption of an IT dubbing application via imitation. Therefore, formal models encompassing the interactions taking place across the different taxonomy categories are required to understand the incentives of DMs when observing and evaluating a given technology. 


\section{Proposed strategic framework}

We model the behavior of a DM that is allowed to acquire information in a sequential manner on a set of products defined by two main characteristics or categories. Given the information acquisition and choice behavior of the DM, firms must decide which category of the product to improve and up to what level when competing with a rival in a duopolistic market.

Building on the demand structure of Di Caprio, Santos Arteaga and Tavana (2014, 2016) and Tavana, Di Caprio and Santos Arteaga (2016a), Tavana, Santos Arteaga, Di Caprio and Tierney (2016c), we propose a non-recursive demand-based environment where the DM decides which information to acquire based on two expected utility functions that must be completely redefined after a new observation takes place. This sequential updating requirement prevents the use of standard dynamic programming techniques applied by the operations research literature. Thus, the proposed analysis employs an information acquisition heuristic determined by the payoffs derived from all the potential interactions between the current and the next acquired information. The non-recursivity of the proposed approach is discussed in detail by Di Caprio et al. (2016) and Tavana et al. (2016a).

Both the heuristic approach and the two categories environment are supported by the limited information assimilation and memory capacities of the DMs when comparing products in basic information evaluation scenarios (Simon, 1955; Samiee, Shimp \& Sharma, 2005). In particular, when analyzing the optimal behavior of DMs within these types of scenarios products are generally restricted to vectors of two characteristics, both in the economic (Malerba, Nelson, Orsenigo \& Winter, 2007) and the operational research and management (Bohlmann, Golder \& Mitra, 2002; Lee, J. \& Lee, J. N., 2009) literatures.

Throughout the paper, we will highlight the main differences between our approach to the information acquisition process of DMs and the standard one employed by the operations research and management literatures, which focuses on the expected value derived from acquiring the next piece of information (Ulu \& Smith, 2009).

Moreover, the current paper also builds on and completes the results obtained in the duopolistic settings of Di Caprio and Santos-Arteaga (2014) and Tavana et al. (2016b). In particular, we study the strategic environment faced by a firm when determining both the category to improve technologically and the intensity of these improvements while competing with a rival firm. Figure 2 provides a schematic representation of the main research on which the current paper is built while outlining its novel contributions.

Figure 3 provides a flowchart based on the different sections of the paper defining the main features of the model and its contributions.

\subsection{Technical assumptions and notations}

Let $G$ denote the set of all products. We assume that each product is described by two main characteristics taking values in two nonempty sets, $X_{1}$ and $X_{2}$. We will refer to them as first and the second factor space, respectively. Thus, a product of $G$ is represented by a pair $\left(x_{1}, x_{2}\right)$ of the Cartesian product $X_{1} \times X_{2}$. 


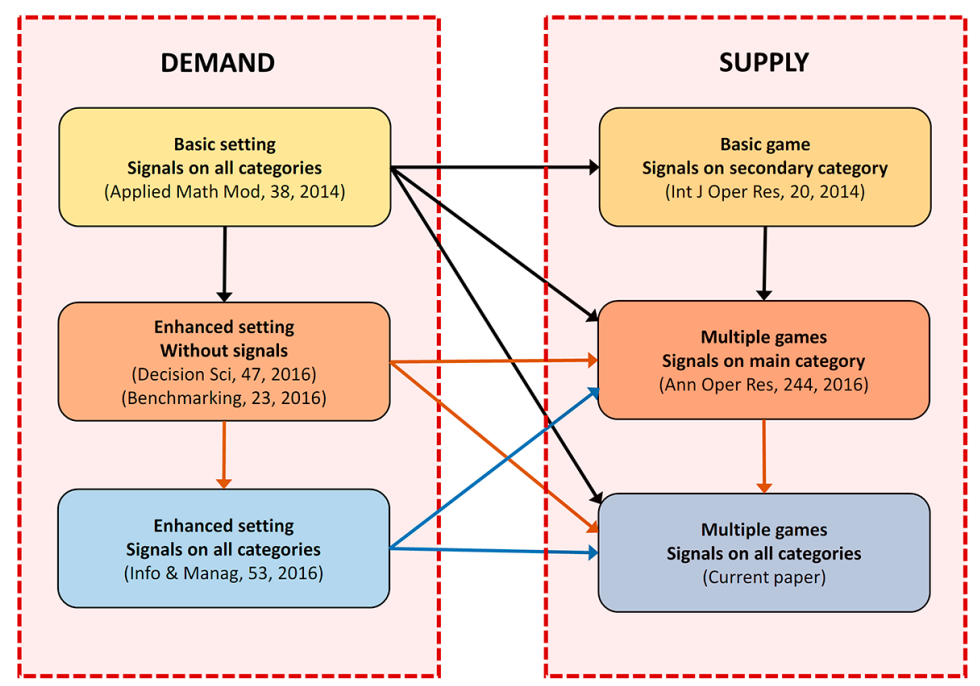

Figure 2. Building blocks of the current research

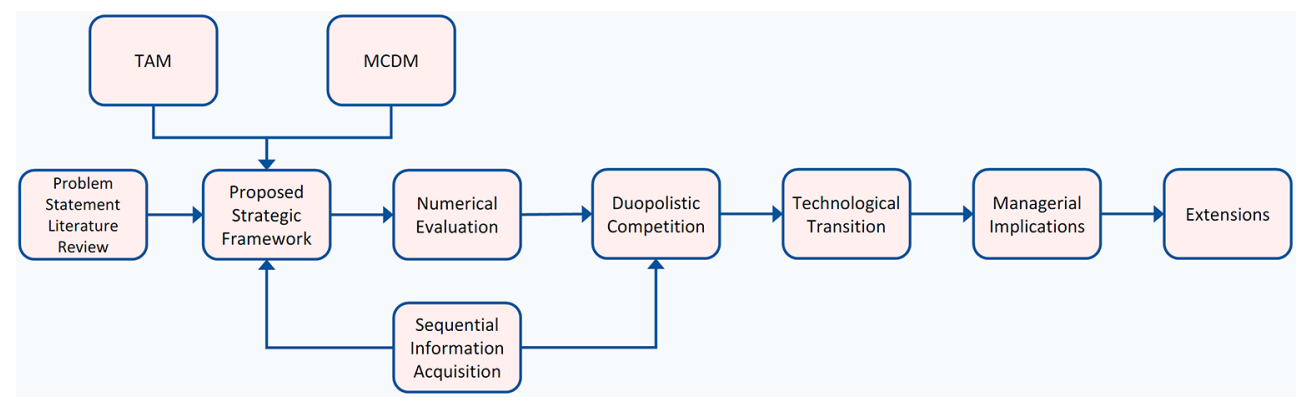

Figure 3. Structure of the current model

We also assume that the first factor space dominates the second. That is, the values taken by the first characteristic are more important to the DM than those taken by the second.

Recall that a preference relation $\succeq$ on $X_{k}, k=1,2$, is a binary relation on $X_{k}$ satisfying reflexivity, completeness and transitivity. A utility function representing $\succeq$ on $X_{k}$ is a function $u_{k}: X_{k} \rightarrow \mathrm{R}$ such that:

$$
\forall x^{\prime}, x^{\prime \prime} \in X_{k}, x^{\prime} \succeq x^{\prime \prime} \Leftrightarrow u_{k}\left(x^{\prime}\right) \geq u_{k}\left(x^{\prime \prime}\right) .
$$

The symbols $\geq$ and $>$ denote the standard partial and linear order on the set $\mathrm{R}$ of all the real numbers.

Following the classical economic approach to consumer information demand, we identify the factor spaces with a closed real subinterval of $[0,+\infty)$, that is, for $k=1,2$ :

$$
X_{k}=\left[x_{k}^{m}, x_{k}^{M}\right]
$$

where $x_{k}^{m}, x_{k}^{M}>0$ and $x_{k}^{m} \neq x_{k}^{M}$. 
Thus, we assume the topology and the preference relation defined by the DM on $X_{k}$ to be those induced by the standard Euclidean topology and the standard linear order <, respectively. As a consequence, the utility function $u_{k}$ can be assumed strictly increasing and continuous, which implies that the sum function $u: X_{1} \times X_{2} \rightarrow \mathrm{R}$ defined by $u\left(x_{1}, x_{2}\right)=u_{1}\left(x_{1}\right)+u_{2}\left(x_{2}\right)$, $\forall\left(x_{1}, x_{2}\right) \in X_{1} \times X_{2}$, is also increasing and represents an additive (Wakker, 1989) preference relation $\succeq_{u}$ on $X_{1} \times X_{2}$ defined as follows:

$$
\left(x_{1}, x_{2}\right) \succeq_{u}\left(x_{1}^{\prime}, x_{2}^{\prime}\right) \stackrel{\text { def }}{\longleftrightarrow} u\left(x_{1}, x_{2}\right) \geq u\left(x_{1}^{\prime}, x_{2}^{\prime}\right) .
$$

We also assume the DM to be endowed with a subjective probability density function over each factor space. Abusing notation, we interpret $X_{k}$ as an absolutely continuous random variable with probability density functions $\mu_{k}: X_{k} \rightarrow[0,1]$. Thus, $\mu_{k}\left(Z_{k}\right)$ is the subjective probability that $x_{k} \in Z_{k} \subseteq X_{k}$ is the value of the $k$-th characteristic of a random product in $G$. The support of $\mu_{k}: X_{k} \rightarrow[0,1]$ is the set $\operatorname{Supp}\left(\mu_{k}\right) \stackrel{\text { def }}{=}\left\{x_{k} \in X_{k}: \mu_{k}\left(x_{k}\right) \neq 0\right\}$.

Following the standard economic theory of choice under uncertainty, we assume that the DM uses the certainty equivalent value of $X_{k}$ as the reference value when checking the value of the $k$-th characteristic of a certain product. For $k=1,2$, the certainty equivalent of $\mu_{k}$ and $u_{k}$ is the following value in $X_{k}$ :

$$
c e_{k}=u_{k}^{-1}\left(E_{k}\right), \text { where } E_{k}=\int_{X_{k}} \mu_{k}\left(x_{k}\right) u_{k}\left(x_{k}\right) d x_{k} .
$$

In other words, $c e_{k}$ is the value in $X_{k}$ that the DM would accept in place of the expected value $E_{k}$ provided by $\mu_{k}$ and $u_{k}$. Note that, in our setting, $c e_{k}$ exists and it is unique due to the continuity and strict increasingness of $u_{k}$, respectively. Finally, note that $E_{1}+E_{2}$ is the utility value that the DM associates to any randomly chosen product.

\subsection{DM's basic decision: continuing observing a product vs starting observing a new one}

Due to the dominance of the first factor space over the second (see Subsection 2.1), the first observation that the DM acquires is the value of the first characteristic of any of the products in $G$. We will refer to this product as the initial product.

Let $x_{1}$ be the value of the first characteristic of the initial product. After observing the value $x_{1}$, the DM must decide whether to observe the value $x_{2}$ of the second characteristic from the same product, or the value $y_{1}$ of the first characteristic of a new product.

Since $E_{1}+E_{2}$ is the utility value that the DM derives from any randomly chosen product, the DM shall prefer a product whose characteristics he has already observed to any randomly chosen product if the observed characteristics deliver a utility higher than $E_{1}+E_{2}$. In other words, the DM shall consider the sum $E_{1}+E_{2}$ as the main reference value when calculating the expected utility ha can derive from acquiring a new observation (Mas-Colell, Whinston \& Green, 1995).

Clearly, the expected utility gain over $E_{1}+E_{2}$ that the DM derives from continuing checking the initial product as well as from starting checking a new one varies with the observed value $x_{1}$. Thus, we need to define two expected utility functions, one measuring the expected 
utility that the DM derives from continuing with the initial product and one measuring the expected utility that the DM derives from starting with a new product.

Following the demand side research described in Figure 2, we denote by $F: X_{1} \rightarrow \mathrm{R}$ and $H: X_{1} \rightarrow \mathrm{R}$ the expected utility functions associated with the continuing and starting options, respectively, and define them as follows.

$$
\begin{aligned}
& F\left(x_{1}\right) \stackrel{d e f}{=} \int_{P^{+}\left(x_{1}\right)} \mu_{2}\left(x_{2}\right)\left(u_{1}\left(x_{1}\right)+u_{2}\left(x_{2}\right)\right) d x_{2}+\int_{P^{-}\left(x_{1}\right)} \mu_{2}\left(x_{2}\right)\left(E_{1}+E_{2}\right) d x_{2} ; \\
& H\left(x_{1}\right)=\int_{Q^{+}\left(x_{1}\right)} \mu_{1}\left(y_{1}\right)\left(u_{1}\left(y_{1}\right)+E_{2}\right) d y_{1}+\int_{Q^{-}\left(x_{1}\right)} \mu_{1}\left(y_{1}\right)\left(\max \left\{u_{1}\left(x_{1}\right), E_{1}\right\}+E_{2}\right) d y_{1},
\end{aligned}
$$

where, for every $x_{1} \in X_{1}$, we have:

$$
\begin{aligned}
& P^{+}\left(x_{1}\right)^{\text {def }}=\left\{x_{2} \in \operatorname{Supp}\left(\mu_{2}\right): u_{2}\left(x_{2}\right)>E_{1}+E_{2}-u_{1}\left(x_{1}\right)\right\} ; \\
& P^{-}\left(x_{1}\right) \stackrel{\text { def }}{=}\left\{x_{2} \in \operatorname{Supp}\left(\mu_{2}\right): u_{2}\left(x_{2}\right) \leq E_{1}+E_{2}-u_{1}\left(x_{1}\right)\right\} \text {; } \\
& Q^{+}\left(x_{1}\right)=\left\{y_{1} \in \operatorname{Supp}\left(\mu_{1}\right): u_{1}\left(y_{1}\right)>\max \left\{u_{1}\left(x_{1}\right), E_{1}\right\}\right\} \text {; } \\
& Q^{-}\left(x_{1}\right)=\left\{y_{1} \in \operatorname{Supp}\left(\mu_{1}\right): u_{1}\left(y_{1}\right) \leq \max \left\{u_{1}\left(x_{1}\right), E_{1}\right\}\right\} \text {. }
\end{aligned}
$$

The crossing points between the graphs of $F$ and $H$ are thresholds that allow the DM to choose the option providing him with the highest expected utility. For a more detailed and technical description of these functions and the logic behind their definition the reader may refer to Di Caprio et al. (2014), where the authors perform a systematic analysis of the conditions guaranteeing the existence of crossing points.

\subsection{Introducing signals and learning}

Positive signals about the distribution of characteristics on $X_{k}, k=1,2$, and the corresponding learning processes affect the expected utility functions associated with the continuing and starting options and, hence, the information acquisition behavior of the DM.

To fix the ideas, we assume that the DM defines two uniform probability density functions on $X_{k}, k=1,2$, that is:

$$
\forall x_{k} \in X_{k}=\left[x_{k}^{m}, x_{k}^{M}\right], \mu_{k}\left(x_{k}\right)=\frac{1}{x_{k}^{M}-x_{k}^{m}} .
$$

This assumption translates into a maximum information entropy setting, where the DM faces complete initial uncertainty (Tavana, 2004). Assuming that the DM believes the signals to provide truthful information about the distribution of the characteristics, the decision environment changes from an uncertain to a risky one.

As in Di Caprio et al. (2014), we assume that after receiving a credible positive signal, $\theta$, about the distribution of characteristics on $X_{k}, k=1,2$, the DM halves the probability mass on $\left[x_{k}^{m}, \frac{x_{k}^{m}+x_{k}^{M}}{2}\right]$ and uses the extra half to increase the probability mass on 
$\left(\frac{x_{k}^{m}+x_{k}^{M}}{2}, x_{k}^{M}\right]$. More precisely, we assume the DM to define the following conditional density function (conditional on the value of $x_{k}$ ):

$$
\begin{aligned}
& \pi_{1}\left(\theta, \gamma \mid x_{k}\right)=\frac{1}{x_{k}^{M}-x_{k}^{m}}+\gamma \frac{1}{x_{k}^{M}-x_{k}^{m}}, \text { if } x_{k} \in\left(\frac{x_{k}^{m}+x_{k}^{M}}{2}, x_{k}^{M}\right] ; \\
& \pi_{2}\left(\theta, \gamma \mid x_{k}\right)=\frac{1}{x_{k}^{M}-x_{k}^{m}}-\gamma \frac{1}{x_{k}^{M}-x_{k}^{m}}, \text { if } x_{k} \in\left[x_{k}^{m}, \frac{x_{k}^{m}+x_{k}^{M}}{2}\right],
\end{aligned}
$$

where $\theta$ is the number of signals on the distribution of $X_{k}$ and $\gamma \in[0,1]$.

The parameter $\gamma$ can be interpreted as a proxy for the quality of the innovation introduced, with higher values leading to a better expected product. Note that the main results obtained in this paper are independent from the value of $\gamma$. Thus, to simplify the presentation, henceforth, we assume that $\gamma=\frac{1}{2}$.

Finally, the DM uses Bayes' rule to update his initial beliefs. That is, as the DM receives a positive signal (i.e., $\theta=1$ ) on the distribution of $X_{k}$, he updates his beliefs from $\mu_{k}\left(x_{k}\right)$ to the following:

$$
\mu_{k}\left(x_{k} \mid \theta=1\right)=\left\{\begin{array}{ll}
\frac{\pi_{1}\left(\theta, \gamma \mid x_{k}\right) \mu_{k}\left(x_{k}\right)}{\int_{X_{k}} \pi_{1}\left(\theta, \gamma \mid x_{k}\right) \mu_{k}\left(x_{k}\right) d x_{k}} & \text { if } x_{k} \in\left[\frac{x_{k}^{m}+x_{k}^{M}}{2}, x_{k}^{M}\right] \\
\frac{\pi_{2}\left(\theta, \gamma \mid x_{k}\right) \mu_{k}\left(x_{k}\right)}{\int_{X_{k}} \pi_{2}\left(\theta, \gamma \mid x_{k}\right) \mu_{k}\left(x_{k}\right) d x_{k}} & \text { if } x_{k} \in\left[x_{k}^{m}, \frac{x_{k}^{m}+x_{k}^{M}}{2}\right]
\end{array}\right. \text {. }
$$

The DM applies the same type of updating process every time he receives a new signal. The expected utility functions defined by the DM using the updated beliefs $\mu_{k}\left(x_{k} \mid \theta\right)$ will be denoted by $F\left(x_{1} \mid \theta\right)$ and $H\left(x_{1} \mid \theta\right)$. The threshold values determined by the expected utility functions defined by the DM before or after receiving signals will be indicated by $x_{1}^{*}$.

\section{Numerical simulations: thresholds and signals}

The numerical simulations in this section illustrate how the threshold values determined by the graphs of $F$ and $H$ change as the number of signals on the distribution of either $X_{1}$ or $X_{2}$ increases.

Consider, as a basic reference, the case of a risk-neutral DM defining uniform probability densities on both $X_{1}$ and $X_{2}$.

- Factor spaces: $X_{1}=[5,10], X_{2}=[0,10]$.

- Utility functions: $\forall x_{1} \in X_{1}, u_{1}\left(x_{1}\right)=x_{1} ; \forall x_{2} \in X_{2}, u_{2}\left(x_{2}\right)=x_{2}$.

- Probability densities: $\forall x_{1} \in X_{1}, \mu_{1}\left(x_{1}\right)=\frac{1}{5} ; \forall x_{2} \in X_{2}, \mu_{2}\left(x_{2}\right)=\frac{1}{10}$.

This case is represented in Figures 4 and 5. Note that in all figures, we used $F(n s), F(1 s)$ and $F(2 s)$ in place of $F\left(x_{1}\right)=F\left(x_{1} \mid \theta=0\right), F\left(x_{1} \mid \theta=1\right)$ and $F\left(x_{1} \mid \theta=2\right)$, respectively.

We also analyze the case of a risk-averse DM. We use the same factor spaces and probability densities as in the risk-neutral case, while the utility functions are defined as follows: 


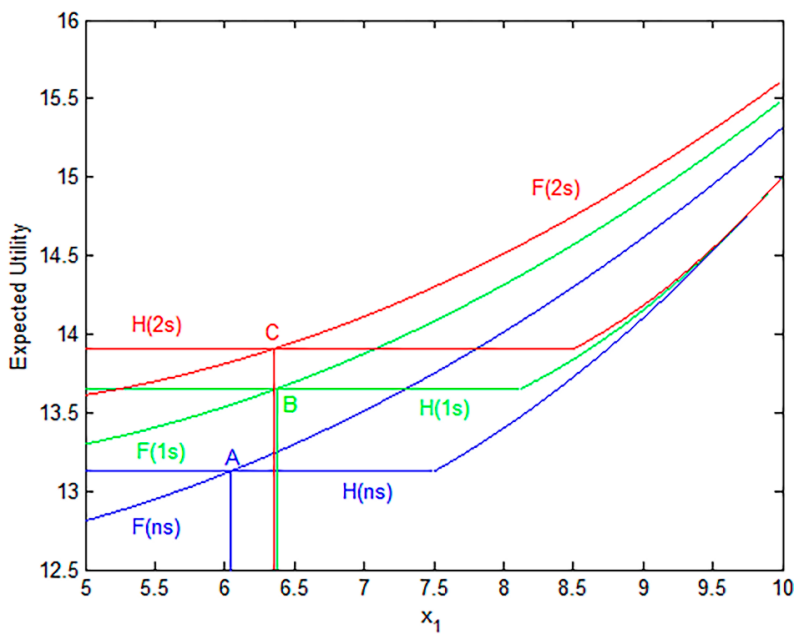

Figure 4. Evolution of thresholds for a risk-neutral DM given uniform beliefs and signals on $X_{1}$

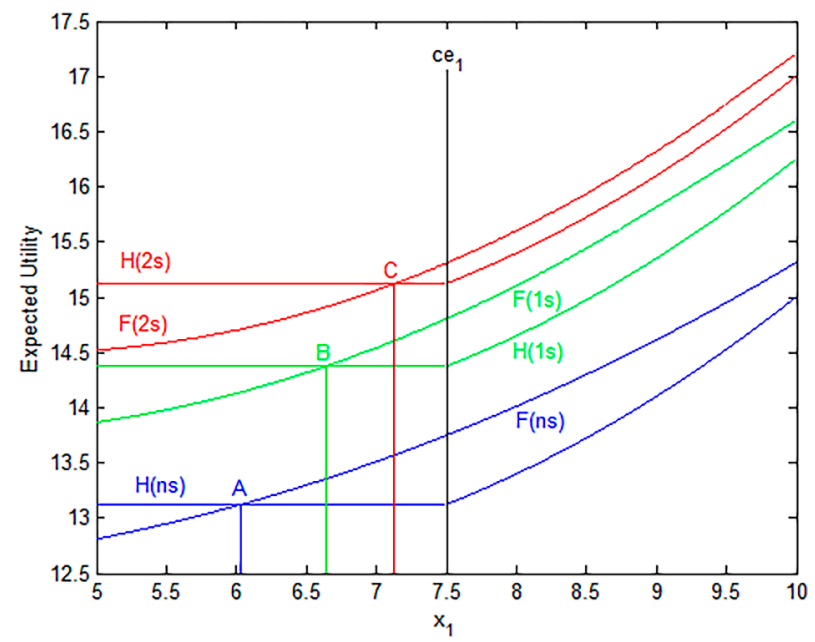

Figure 5. Evolution of thresholds for a risk-neutral DM given uniform beliefs and signals on $X_{2}$

- Utility functions: $\forall x_{1} \in X_{1}, u_{1}\left(x_{1}\right)=\sqrt{x_{1}} ; \forall x_{2} \in X_{2}, u_{2}\left(x_{2}\right)=\sqrt{x_{2}}$.

This case is represented in Figures 6 and 7.

It can be shown analytically that if $\mu_{k}\left(x_{k} \mid \theta\right)$ first-order stochastically dominates $\mu_{k}\left(x_{k}\right)$, with $k=1,2$, then $F\left(x_{1} \mid \theta\right) \geq F\left(x_{1}\right)$ and $H\left(x_{1} \mid \theta\right) \geq H\left(x_{1}\right)$. That is, if a positive signal generates first order stochastic dominant beliefs, then the corresponding expected utility levels are higher than those associated with the initial beliefs (Tavana et al., 2016b).

At the same time, increasing the number of signals may cause the optimal threshold values determined by the corresponding expected utility functions to shift rightwards, towards higher realizations of $x_{1}$. As shown in Figures 5 and 7, this is particularly true when signals are issued on the second characteristic. This pattern is reversed when considering 
improvements on $X_{1}$, as Figures 4 and 6 illustrate. This difference is mainly due to the larger increment in the reference utility value $E_{1}+E_{2}$ that takes place when improvements are introduced on the second characteristic.

Figures 4 to 7 illustrate a fundamental advantage of our approach over the standard one that considers the expected value of the characteristics as a reference threshold. In the standard expected-value based setting, modifications in the distribution of the second characteristic do not have any effect on the behavior of the DM when acquiring information on the first characteristic: the threshold value remains fixed at $c e_{1}$. In our approach, modifications in the distribution of the second characteristic have a direct effect on the threshold value $x_{1}^{*}$ considered by the DM for the first characteristic.

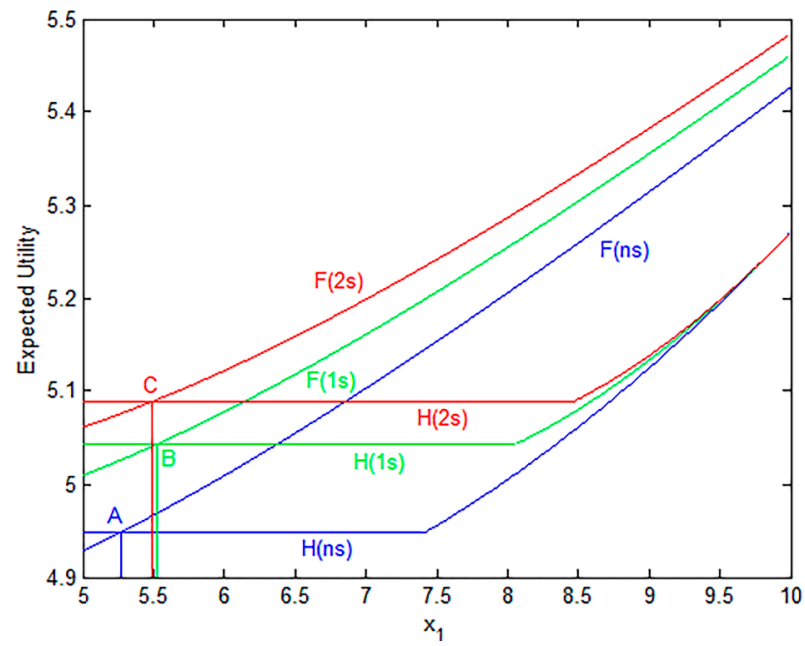

Figure 6. Evolution of thresholds for a risk-averse DM given uniform beliefs and signals on $X_{1}$

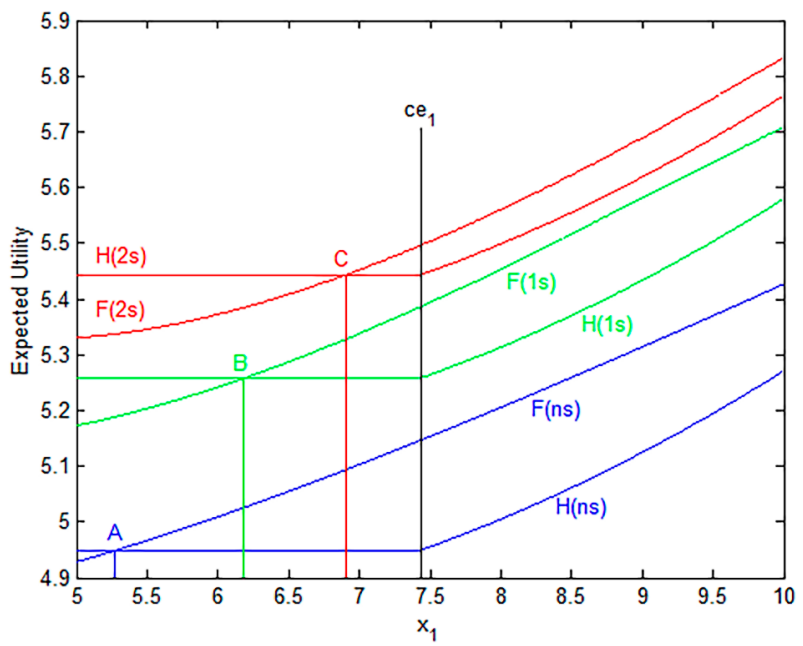

Figure 7. Evolution of thresholds for a risk-averse DM given uniform beliefs and signals on $X_{2}$ 


\section{Technological transition: incorporating supply}

In this section, we define a basic strategic structure that accounts for the introduction of technologically superior products, given the behavior of the optimal threshold values identified in the previous section. More precisely, we define a pre-commitment signaling duopolistic environment where firms must decide strategically the level of technological improvement of the products being introduced.

We assume the technological superiority of a set of products to be represented by the stochastic dominance of its distribution on $X_{1}$ or $X_{2}$. The expected utilities defined in Section 3 can be interpreted as the information acquisition incentives of the DM. These utility values also define the expected profits of the firms. That is, given the distribution of product characteristics made available by a firm, its expected profits depend on its ability to provide the characteristics required by the DMs.

In fact, the DM should refrain from purchasing a certain product if the characteristics observed for it after gathering information do not deliver an expected utility higher than $E_{1}+E_{2}$ in the unsignaled market or higher than $E_{(1 \mid \theta=j)}+E_{2}$ or $E_{1}+E_{(2 \mid \theta=j)}$, with $j=1,2,3$ , in the signaled ones. On the other hand, the possibility of randomly choosing a product provides not only the DM but also the market with a clear reference point when designing their respective search strategies.

Two different information acquisition structures will be considered depending on the total number of observations acquired by a DM.

As already emphasized when describing Figure 1, most of the device and service characteristics of the product are verifiable to some extent before the purchase takes place while the facilitating conditions require a more detailed analysis. In order to simplify the presentation, assume that most of the characteristics composing $X_{1}$ are verifiable while most of those composing $X_{2}$ require a more detailed analysis of the product. This property relates the information acquisition structure to the literature on price versus experience components of products following the seminal paper of Nelson (1970).

We will assume that the DM performs a more exhaustive analysis of the products provided by firms when the market is in the early stages of development. That is, given the novelty of the products and the lack of knowledge regarding their characteristics, the DM is willing to completely observe a product before purchasing it. Within a standard duopolistic environment, this implies that the DM is willing to observe a maximum of four characteristics, i.e. one product fully from each firm. The corresponding information acquisition and purchase process is represented in Figure 8.

Given the fast replacement of products with new features taking place in the market for consumer electronics (Prabhakar Murthy, Rausand \& Østerås, 2008), the DM may not be willing to observe more than one product completely. In other words, once the DM decides to observe a subset of experience components defining the second characteristic from the product of a given firm, its rival will have to wait for new product improvements to be introduced before being able to consider the purchase of its products by the DM. That is, a complete analysis of a given product through a trial period exhausts the willingness of the $\mathrm{DM}$ to acquire information within the market. As a result, if the product fully observed does not provide a sufficiently high utility, the DM will delay his purchase decision until the next set of product improvements is introduced (Greenleaf \& Lehmann, 1995). 


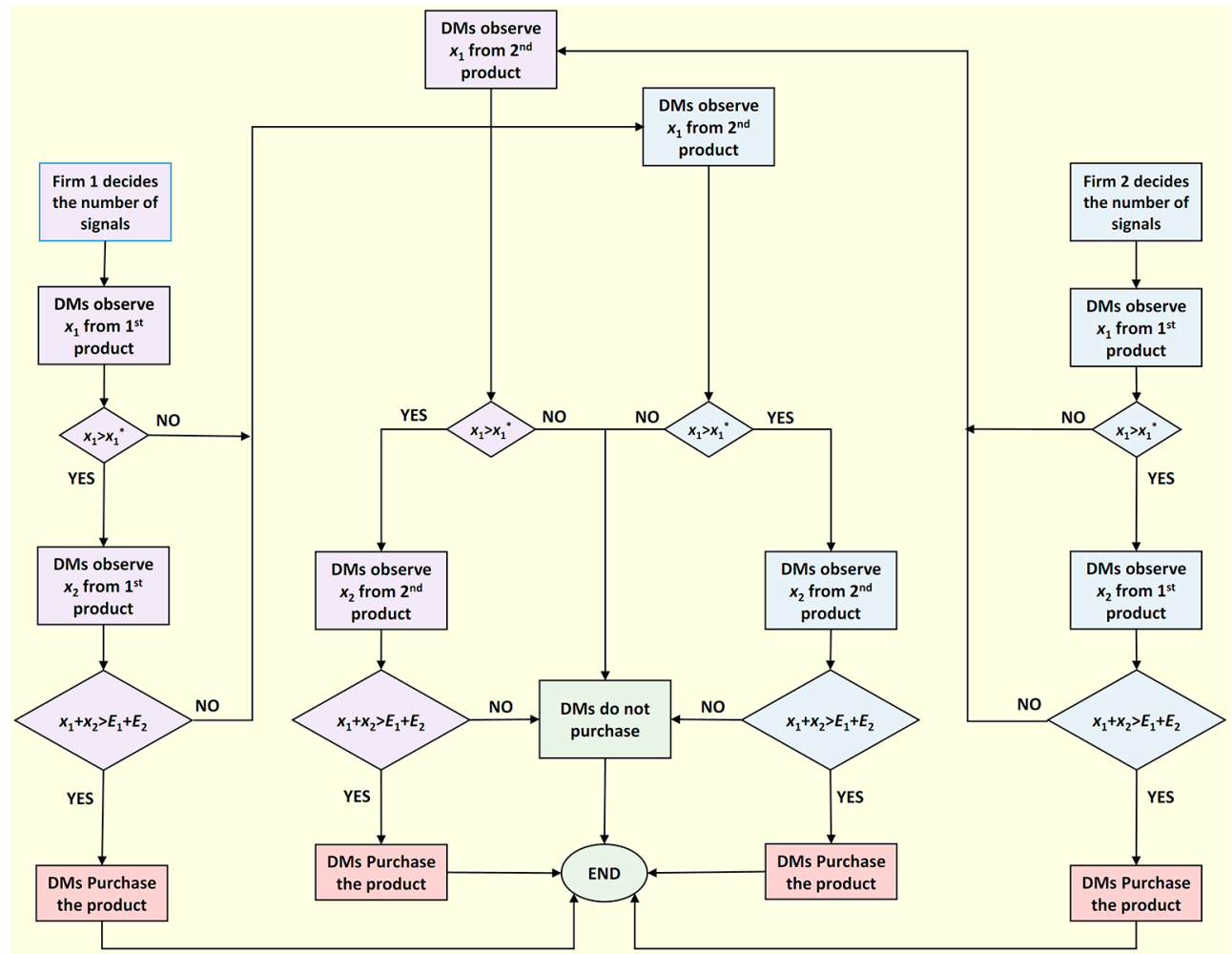

Figure 8. Information acquisition process, purchase decisions and market development

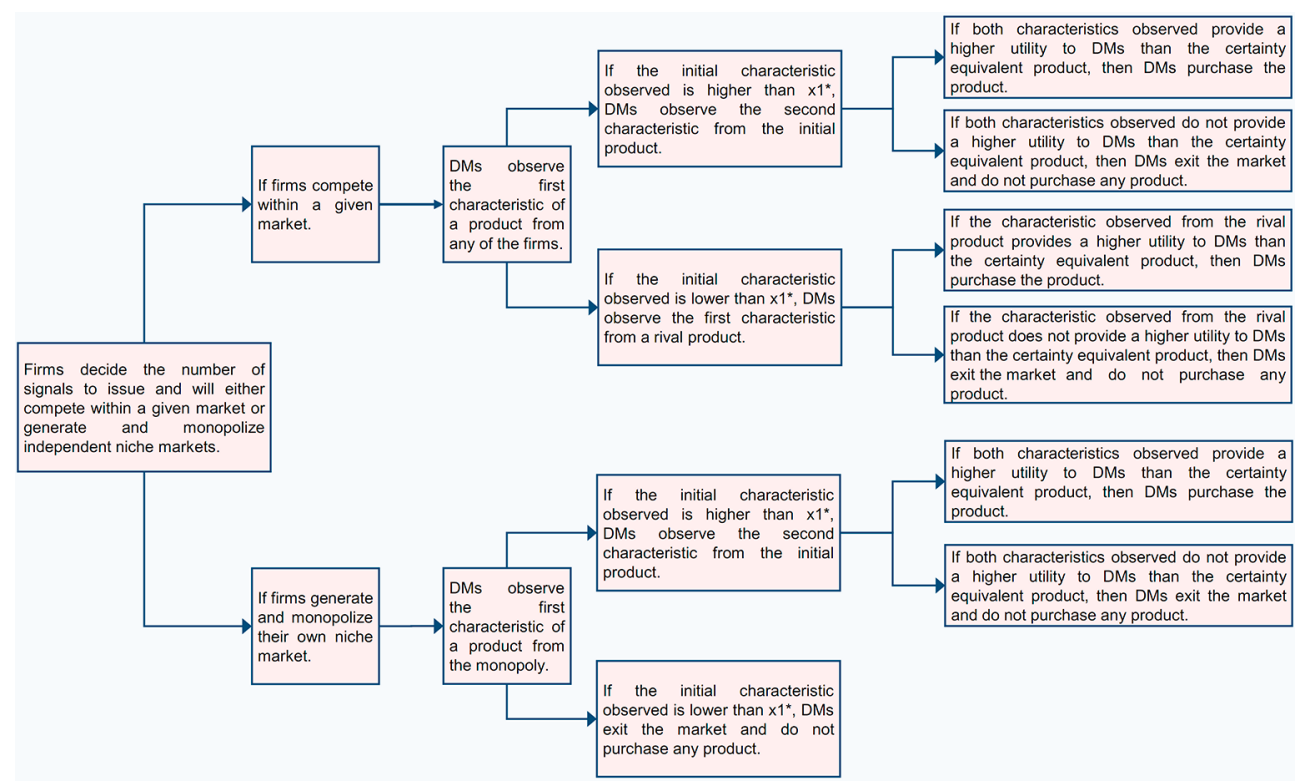

Figure 9. Information acquisition process within a developing product market 
Within a standard duopolistic environment, the willingness of the DM to completely observe only one product implies that he will observe a maximum of two characteristics, i.e. either one product fully from a firm or two products partially, one from a firm and the other from its rival. That is, a partial not exhaustive analysis of an initial product allows the DM to acquire additional information from a different product on which to base his purchase decision. The corresponding information acquisition and purchase process is represented in Figure 9.

In the following section, we calculate the changes in the rejection probabilities of firms due to their different signaling strategies and the information acquisition behavior of the DM.

\subsection{Numerical analysis of the two-observations setting}

Firms must consider the rejection probabilities when deciding how many signals to issue, since the number of signals determines the expected outcome derived from either monopolizing or competing with other firms within a given technological market. The corresponding signaling strategies are therefore defined in terms of their choice of the product characteristics that need to be improved upon, i.e. the technological market, and the number of signals that will be issued on the chosen characteristic, i.e. the intensity of the improvement.

In the setting with two observations, the rejection probability faced by the unique firm monopolizing a given technological market is expressed as follows:

$$
\mu_{1}\left(x_{1}<x_{1}^{*} \mid \theta=s\right)+\mu_{1}\left(x_{1}>x_{1}^{*} \mid \theta=s\right) \mu_{2}\left(x_{2}<x_{2}^{*} \mid x_{1}\right),
$$

where $x_{2}^{*}$ is such that

$$
u_{1}\left(x_{1}\right)+u_{2}\left(x_{2}^{*}\right)=E_{(1 \mid \theta=s)}+E_{2}, \text { for } s=1, \ldots, 3,
$$

if signals are issued on the first characteristic, and such that

$$
u_{1}\left(x_{1}\right)+u_{2}\left(x_{2}^{*}\right)=E_{1}+E_{(2 \mid \theta=s)}, \text { for } s=1, \ldots, 3,
$$

if signals are issued on the second characteristic.

In fact, in the case of a monopolistic firm, rejection takes place if the value of the first characteristic of the initially observed product is located above $x_{1}^{*}$ and the value of the second one is acceptable (this is accounted for by the term $\mu_{1}\left(x_{1}>x_{1}^{*} \mid \theta=s\right) \mu_{2}\left(x_{2}<x_{2}^{*} \mid x_{1}\right)$ ), or if the value observed for the first characteristics is located below $x_{1}^{*}$ (this is represented by the term $\left.\mu_{1}\left(x_{1}<x_{1}^{*} \mid \theta=s\right)\right)$. Otherwise, the DM purchases a product from the monopolistic firm.

Moreover, Equation (14) and Equation (15) lead respectively to

$$
\mu_{1}\left(x_{1}>x_{1}^{*} \mid \theta=s\right) \mu_{2}\left(x_{2}<x_{2}^{*} \mid x_{1}\right)=\int_{x_{1}^{*}}^{x_{1}^{M}} \mu_{1}\left(x_{1} \mid \theta=s\right)\left[\int_{0}^{c e_{(1 \mid \theta=s)}+c e_{2}-x_{1}} \mu_{2}\left(x_{2}\right) d x_{2}\right] d x_{1},
$$

and

$$
\mu_{1}\left(x_{1}>x_{1}^{*} \mid \theta=s\right) \mu_{2}\left(x_{2}<x_{2}^{*} \mid x_{1}\right)=\int_{x_{1}^{*}}^{x_{1}^{M}} \mu_{1}\left(x_{1} \mid \theta=s\right)\left[\int_{0}^{c e_{1}+c e_{(2 \mid \theta=s)}-x_{1}} \mu_{2}\left(x_{2} \mid \theta=s\right) d x_{2}\right] d x_{1} \text {. }
$$


On the other hand, when two identical firms compete within a given market as a duopoly, the rejection probability becomes as follows:

$$
\begin{aligned}
& \frac{1}{2} \mu_{1}\left(x_{1}<x_{1}^{*} \mid \theta=s\right)+\frac{1}{2} \mu_{1}\left(x_{1}>x_{1}^{*} \mid \theta=s\right) \mu_{2}\left(x_{2}<x_{2}^{*} \mid x_{1}\right)+ \\
& \frac{1}{2} \mu_{1}^{\prime}\left(x_{1}^{\prime}>x_{1}^{*} \mid \theta=s\right)+\frac{1}{2} \mu_{1}^{\prime}\left(x_{1}^{\prime}<x_{1}^{*} \mid \theta=s\right) \mu_{1}\left(x_{1}<c e_{1} \mid \theta=s\right),
\end{aligned}
$$

where the prime superindex refers to the rival firm. Since, within the current setting, firms are assumed to be identical and indistinguishable, we conclude that $\mu_{1}^{\prime}\left(x_{1}^{\prime}<x_{1}^{*} \mid \theta=s\right)=\mu_{1}\left(x_{1}<x_{1}^{*} \mid \theta=s\right)$, from which we derive the following rejection probability

$$
\begin{aligned}
& \frac{1}{2} \mu_{1}\left(x_{1}<x_{1}^{*} \mid \theta=s\right)+\frac{1}{2} \mu_{1}\left(x_{1}>x_{1}^{*} \mid \theta=s\right) \mu_{2}\left(x_{2}<x_{2}^{*} \mid x_{1}\right)+ \\
& \frac{1}{2} \mu_{1}\left(x_{1}>x_{1}^{*} \mid \theta=s\right)+\frac{1}{2}\left[\mu_{1}\left(x_{1}<x_{1}^{*} \mid \theta=s\right) \mu_{1}\left(x_{1}<c e_{1} \mid \theta=s\right)\right] .
\end{aligned}
$$

The indistinguishability of the duopolistic firms has been assumed to emphasize the strength of the results obtained regarding their signaling incentives. Clearly, brand differences and any other exogenous or endogenous effects affecting the beliefs or the behavior of DMs would modify the numerical results obtained.

The monopolistic and duopolistic rejection probabilities corresponding to the risk-neutral and risk-averse cases will be used to define the technological transition matrices presented in Section 6.

\subsection{Numerical analysis of the four-observations setting}

Given the $x_{1}^{*}$-based heuristic defined using the expected search utilities, the previous setting can be extended to account for the acquisition of additional information by the DM. Changes in the willingness to search of the DM will modify the payoffs expected to be obtained by the firms as well as their signaling incentives.

In the setting with four observations, the rejection probability faced by the unique firm monopolizing a technological market is still given by Eq. (13). However, the payoffs obtained within a duopolistic environment needs to be considerably modified.

Given the indistinguishability assumption, the rejection probability faced by a firm when competing within a duopolistic symmetric environment is

$$
\begin{aligned}
& \frac{1}{2} \mu_{1}\left(x_{1}<x_{1}^{*} \mid \theta=s\right)+\frac{1}{2} \mu_{1}\left(x_{1}>x_{1}^{*} \mid \theta=s\right) \mu_{2}\left(x_{2}<x_{2}^{*} \mid x_{1}\right)+ \\
& \frac{1}{2} \mu_{1}^{\prime}\left(x_{1}^{\prime}>x_{1}^{*} \mid \theta=s\right) \mu_{2}^{\prime}\left(x_{2}^{\prime}>x_{2}^{*} \mid x_{1}^{\prime}\right)+ \\
& \frac{1}{2} \mu_{1}^{\prime}\left(x_{1}^{\prime}>x_{1}^{*} \mid \theta=s\right) \mu_{2}^{\prime}\left(x_{2}^{\prime}<x_{2}^{*} \mid x_{1}^{\prime}\right)\left[\mu_{1}\left(x_{1}<x_{1}^{*} \mid \theta=s\right)+\mu_{1}\left(x_{1}>x_{1}^{*} \mid \theta=s\right) \mu_{2}\left(x_{2}<x_{2}^{*} \mid x_{1}\right)\right]+ \\
& \frac{1}{2} \mu_{1}^{\prime}\left(x_{1}^{\prime}<x_{1}^{*} \mid \theta=s\right)\left[\mu_{1}\left(x_{1}<x_{1}^{*} \mid \theta=s\right)+\mu_{1}\left(x_{1}>x_{1}^{*} \mid \theta=s\right) \mu_{2}\left(x_{2}<x_{2}^{*} \mid x_{1}\right)\right] .
\end{aligned}
$$

Two contrasting effects can be observed when comparing Eqs (18) and (20). On one hand, Eq. (20) shows a decrease in the rejection probability faced by a firm due to the willingness of the DM to observe characteristics from the products offered by the firm even if the 
initial realization from the rival is $x_{1}^{\prime}>x_{1}^{*}$. On the other, an ambiguous effect is obtained for realizations of $x_{1}^{\prime}<x_{1}^{*}$. In this case, the rejection probability determined by the new observation in terms of the certainty equivalent value must be compared with that following from two potential observations based on $x_{1}^{*}$.

The monopolistic and duopolistic rejection probabilities corresponding to the risk-neutral and risk-averse cases will be used to define the symmetric technological transition matrices provided in Section 6. Given the numerical framework considered, these matrices illustrate how allowing the DM to acquire additional observations leads to a decrease in the duopolistic rejection probability faced by the firms.

\section{Technological transition: mixed strategies}

Consider a standard symmetric economic duopoly based on a unique signal being issued. Each identical firm can either signal the introduction of an improved set of product characteristics $X_{k}$ (with $k=1,2$ ), 1 , or not signal it, $n s$. Let $E[r(\mu)]_{A}$ be the current expected profit obtained by each firm if none of them signals and each must compete for the DMs with respect to threshold $A$, see Figures 4 to 7 . Similarly, let $E[r(\theta)]_{B}$ be the expected profit obtained by a firm from unilaterally signaling and facing less search averse DMs at threshold $B$. Clearly, if both firms signal the improvement, they must compete for the DMs in the corresponding market. This leads to an expected payoff, denoted by $\left(<E[r(\theta)]_{B}\right)$, strictly smaller than the one obtained in a monopolistic environment with only one firm signaling the improvement.

The resulting transition game between technologies corresponds to the initial (ns versus 1s) subgame represented in Table 1 . The other two technological transition subgames described in Table 1, which account for the $1 s$ versus $2 s$ and the $2 s$ versus $3 s$ scenarios, follow the same intuition.

Table 1. Technological transition game with signals on $X_{k}, k=1,2$

\begin{tabular}{|c|c|c|c|c|}
\hline & $\boldsymbol{3 s}$ & $\boldsymbol{2 s}$ & $\mathbf{1 s}$ & $\boldsymbol{n s}$ \\
\hline $\boldsymbol{3 s}$ & $\left(<E[r(\theta)]_{D}\right)$ & $E[r(\theta)]_{D}, 0$ & $E[r(\theta)]_{D}, 0$ & $E[r(\theta)]_{D}, 0$ \\
\hline $\mathbf{2} \boldsymbol{s}$ & $0, E[r(\theta)]_{D}$ & $\left(<E[r(\theta)]_{C}\right)$ & $E[r(\theta)]_{C}, 0$ & $E[r(\theta)]_{C}, 0$ \\
\hline $\mathbf{1 s}$ & $0, E[r(\theta)]_{D}$ & $0, E[r(\theta)]_{C}$ & $\left(<E[r(\theta)]_{B}\right)$ & $E[r(\theta)]_{B}, 0$ \\
\hline $\boldsymbol{n s}$ & $0, E[r(\theta)]_{D}$ & $0, E[r(\theta)]_{C}$ & $0, E[r(\theta)]_{B}$ & $E[r(\mu)]_{A}$ \\
\hline
\end{tabular}

We will use the superindex $x$ to differentiate the payoffs obtained in the $X_{1}$-based signaling setting from those corresponding to the $X_{2}$-based one, where no superindex has been added. The next theorem follows immediately from the current formal strategic structure.

Theorem 6.1. Assume that signaling is a (strictly) dominant strategy in all the sequential subgames with both the $X_{1}$ and $X_{2}$ scenarios. That is, assume that

$$
\begin{aligned}
& E[r(\theta)]_{D}^{x}>\left(<E[r(\theta)]_{C}^{x}\right) ; E[r(\theta)]_{C}^{x}>\left(<E[r(\theta)]_{B}^{x}\right) ; E[r(\theta)]_{B}^{x}>E[r(\mu)]_{A}^{x} ; \\
& E[r(\theta)]_{D}>\left(<E[r(\theta)]_{C}\right) ; E[r(\theta)]_{C}>\left(<E[r(\theta)]_{B}\right) ; E[r(\theta)]_{B}>E[r(\mu)]_{A} ; \\
& \left(<E[r(\theta)]_{l}^{x}\right)>0 \text { and }\left(<E[r(\theta)]_{l}\right)>0,
\end{aligned}
$$


for $l=D, C, B$. Firms will coordinate with certainty on improving the first characteristic and issuing the maximum possible number of signals if and only if

$$
\left(<E[r(\theta)]_{D}^{x}>E[r(\theta)]_{D}\right) .
$$

An analogous condition can be stated when considering the second characteristic.

This theorem highlights the potential coordination incentives that firms may face when developing technological improvements and provides a demand-based approach to the competition versus specialization economic debate (Rosen, 1974; Weitzman, 1994), when different product characteristics are explicitly considered. Clearly, both firms will compete by improving products to their highest possible intensity level and issuing the corresponding maximum number of signals when the condition stated in the theorem is satisfied. Otherwise, the resulting equilibrium will be defined in mixed strategies, with firms potentially improving any of the two characteristics though not necessarily to their highest possible intensity level. We analyze this environment numerically in the following subsection.

\subsection{Numerical analysis of the technological transition}

In this section, we will first derive several formal results common to both the two and four observations settings. Then, the mixed strategy equilibria corresponding to each setting will be computed and compared.

Consider the duopolistic environment with identical competitors described in the previous section. The risk-neutral and risk-averse technological transition matrices obtained within the two observations setting are described by Tables 2-3 and Tables 4-5, respectively.

Table 2. Technological transition: two observations, risk-neutral DM, and signals on $X_{1}$

\begin{tabular}{|c|c|c|c|c|c|}
\hline \multicolumn{2}{|c|}{} & \multicolumn{4}{c|}{ Firm } \\
\cline { 3 - 6 } \multicolumn{2}{|c|}{} & $\mathbf{3 s}$ & $\mathbf{2 s}$ & $\mathbf{1 s}$ & $\boldsymbol{n s}$ \\
\hline \multirow{4}{*}{ Rival } & $3 \boldsymbol{s}$ & $(0.7472,0.7472)$ & $(0.5036,1)$ & $(0.5036,1)$ & $(0.5036,1)$ \\
\cline { 2 - 6 } & $\mathbf{2}$ & $(1,0.5036)$ & $(0.7424,0.7424)$ & $(0.5117,1)$ & $(0.5117,1)$ \\
\cline { 2 - 6 } & $\mathbf{1 s}$ & $(1,0.5036)$ & $(1,0.5117)$ & $(0.7333,0.7333)$ & $(0.5352,1)$ \\
\cline { 2 - 6 } & $\boldsymbol{n s}$ & $(1,0.5036)$ & $(1,0.5117)$ & $(1,0.5352)$ & $(0.7295,0.7295)$ \\
\hline
\end{tabular}

Table 3. Technological transition: two observations, risk-neutral DM, and signals on $X_{2}$

\begin{tabular}{|c|c|c|c|c|c|}
\hline \multicolumn{2}{|c|}{} & \multicolumn{4}{c|}{ Firm } \\
\cline { 3 - 6 } \multicolumn{2}{|c|}{} & $\boldsymbol{3 s}$ & $\mathbf{2 s}$ & $\mathbf{1 s}$ & $\boldsymbol{n s}$ \\
\hline \multirow{4}{*}{ Rival } & $\mathbf{3 s}$ & $(0.6858,0.6858)$ & $(0.6084,1)$ & $(0.6084,1)$ & $(0.6084,1)$ \\
\cline { 2 - 6 } & $\mathbf{2}$ & $(1,0.6084)$ & $(0.6855,0.6855)$ & $(0.5845,1)$ & $(0.5845,1)$ \\
\cline { 2 - 6 } & $\mathbf{1 s}$ & $(1,0.6084)$ & $(1,0.5845)$ & $(0.6955,0.6955)$ & $(0.5547,1)$ \\
\cline { 2 - 6 } & $\boldsymbol{n s}$ & $(1,0.6084)$ & $(1,0.5845)$ & $(1,0.5547)$ & $(0.7295,0.7295)$ \\
\hline
\end{tabular}


Table 4. Technological transition: two observations, risk-averse DM, and signals on $X_{1}$

\begin{tabular}{|c|c|c|c|c|c|}
\hline \multicolumn{2}{|c|}{} & \multicolumn{4}{|c|}{ Firm } \\
\cline { 3 - 6 } \multicolumn{2}{|c|}{} & $\boldsymbol{3 s}$ & $\mathbf{2 s}$ & $\mathbf{1 s}$ & $\boldsymbol{n s}$ \\
\hline \multirow{4}{*}{ Rival } & $\boldsymbol{3 s}$ & $(0.7225,0.7225)$ & $(0.4481,1)$ & $(0.4481,1)$ & $(0.4481,1)$ \\
\cline { 2 - 6 } & $\mathbf{2}$ & $(1,0.4481)$ & $(0.7215,0.7215)$ & $(0.4528,1)$ & $(0.4528,1)$ \\
\cline { 2 - 6 } & $\mathbf{1}$ & $(1,0.4481)$ & $(1,0.4528)$ & $(0.7192,0.7192)$ & $(0.4656,1)$ \\
\cline { 2 - 6 } & $\boldsymbol{n s}$ & $(1,0.4481)$ & $(1,0.4528)$ & $(1,0.4656)$ & $(0.7211,0.7211)$ \\
\hline
\end{tabular}

Table 5. Technological transition: two observations, risk-averse DM, and signals on $X_{2}$

\begin{tabular}{|c|c|c|c|c|c|}
\hline & \multicolumn{4}{|c|}{ Firm } \\
\hline & & $3 s$ & $2 s$ & $1 s$ & $n s$ \\
\hline \multirow{4}{*}{ Rival } & $3 s$ & $(0.6794,0.6794)$ & $(0.5887,1)$ & $(0.5887,1)$ & $(0.5887,1)$ \\
\hline & $2 s$ & $(1,0.5887)$ & $(0.6749,0.6749)$ & $(0.545,1)$ & $(0.545,1)$ \\
\hline & $1 s$ & $(1,0.5887)$ & $(1,0.545)$ & $(0.6816,0.6816)$ & $(0.4848,1)$ \\
\hline & $n s$ & $(1,0.5887)$ & $(1,0.545)$ & $(1,0.4848)$ & $(0.7211,0.7211)$ \\
\hline
\end{tabular}

Similarly, the risk-neutral and risk-averse technological transition matrices obtained within the four observations setting are described by Tables 6-7 and Tables 8-9, respectively.

Table 6. Technological transition: four observations, risk-neutral DM, and signals on $X_{1}$

\begin{tabular}{|c|c|c|c|c|c|}
\hline & \multicolumn{4}{|c|}{ Firm } \\
\hline & & $3 s$ & $2 s$ & $1 s$ & $n s$ \\
\hline \multirow{4}{*}{ Rival } & $3 s$ & $(0.6268,0.6268)$ & $(0.5036,1)$ & $(0.5036,1)$ & $(0.5036,1)$ \\
\hline & $2 s$ & $(1,0.5036)$ & $(0.6309,0.6309)$ & $(0.5117,1)$ & $(0.5117,1)$ \\
\hline & $1 s$ & $(1,0.5036)$ & $(1,0.5117)$ & $(0.6432,0.6432)$ & $(0.5352,1)$ \\
\hline & $n s$ & $(1,0.5036)$ & $(1,0.5117)$ & $(1,0.5352)$ & $(0.6582,0.6582)$ \\
\hline
\end{tabular}

Table 7. Technological transition: four observations, risk-neutral DM, and signals on $X_{2}$

\begin{tabular}{|c|c|c|c|c|c|}
\hline \multicolumn{2}{|c|}{} & \multicolumn{4}{|c|}{ Firm } \\
\cline { 3 - 6 } \multicolumn{2}{|c|}{} & $\boldsymbol{3 s}$ & $\mathbf{2 s}$ & $\mathbf{1 s}$ & $\boldsymbol{n s}$ \\
\hline \multirow{4}{*}{ Rival } & $\boldsymbol{s}$ & $(0.6851,0.6851)$ & $(0.6084,1)$ & $(0.6084,1)$ & $(0.6084,1)$ \\
\cline { 2 - 6 } & $\mathbf{2}$ & $(1,0.6084)$ & $(0.6708,0.6708)$ & $(0.5845,1)$ & $(0.5845,1)$ \\
\cline { 2 - 6 } & $\mathbf{1}$ & $(1,0.6084)$ & $(1,0.5845)$ & $(0.6538,0.6538)$ & $(0.5547,1)$ \\
\cline { 2 - 6 } & $\boldsymbol{n s}$ & $(1,0.6084)$ & $(1,0.5845)$ & $(1,0.5547)$ & $(0.6582,0.6582)$ \\
\hline
\end{tabular}

Table 8. Technological transition: four observations, risk-averse DM, and signals on $X_{1}$

\begin{tabular}{|c|c|c|c|c|c|}
\hline & \multicolumn{4}{|c|}{ Firm } \\
\hline & & $3 s$ & $2 s$ & $1 s$ & $n s$ \\
\hline \multirow{4}{*}{ Rival } & $3 s$ & $(0.6004,0.6004)$ & $(0.4481,1)$ & $(0.4481,1)$ & $(0.4481,1)$ \\
\hline & $2 s$ & $(1,0.4481)$ & $(0.6025,0.6025)$ & $(0.4528,1)$ & $(0.4528,1)$ \\
\hline & $1 s$ & $(1,0.4481)$ & $(1,0.4528)$ & $(0.6084,0.6084)$ & $(0.4656,1)$ \\
\hline & $n s$ & $(1,0.4481)$ & $(1,0.4528)$ & $(1,0.4656)$ & $(0.6104,0.6104)$ \\
\hline
\end{tabular}


Table 9. Technological transition: four observations, risk-averse DM, and signals on $X_{2}$

\begin{tabular}{|c|c|c|c|c|c|}
\hline \multicolumn{2}{|c|}{} & \multicolumn{4}{|c|}{ Firm } \\
\cline { 3 - 6 } \multicolumn{2}{|c|}{} & $\boldsymbol{3 s}$ & $\mathbf{2 s}$ & $\mathbf{1 s}$ & $\boldsymbol{n s}$ \\
\hline \multirow{4}{*}{ Rival } & $\mathbf{s}$ & $(0.6733,0.6733)$ & $(0.5887,1)$ & $(0.5887,1)$ & $(0.5887,1)$ \\
\cline { 2 - 6 } & $\mathbf{2 s}$ & $(1,0.5887)$ & $(0.6485,0.6485)$ & $(0.545,1)$ & $(0.545,1)$ \\
\cline { 2 - 6 } & $\mathbf{1} \boldsymbol{s}$ & $(1,0.5887)$ & $(1,0.545)$ & $(0.6175,0.6175)$ & $(0.4848,1)$ \\
\cline { 2 - 6 } & $\boldsymbol{n s}$ & $(1,0.5887)$ & $(1,0.545)$ & $(1,0.4848)$ & $(0.6104,0.6104)$ \\
\hline
\end{tabular}

When calculating the rejection probabilities and the corresponding entrances within the technological transition matrices presented in Tables 2 to 9, we validate the intuition that follows from Figures 4 to 7 implying that risk-neutral DMs lead firms to face higher rejection probabilities than risk-averse ones. Given the identical probability densities and signals defined on $X_{1}$ and $X_{2}$ within both scenarios, the difference in rejection probabilities is clearly due to the respective threshold values being higher under risk-neutrality, requiring a better first characteristic observed from the initial product in order for DMs to consider purchasing it.

The numerical entries defining the above technological transition matrices yield the following results, which hold for both the risk-neutral and risk-averse scenarios.

Proposition 6.2. Each technological transition matrix considered individually has a unique equilibrium induced by a dominant strategy to issue the maximum possible number of signals. -

That is, the strictly dominant strategies arising within each sequential subgame composing a technological transition matrix lead firms to issue an additional signal given the payoffs derived from the previous subgame. Note that the subgames composing the $X_{1}$-based scenario within the two observations setting are characterized by prisoner's dilemma type structures while the subgames composing the $X_{2}$-based scenario provide strictly dominant signaling incentives. Note also that this trend is reversed when considering the four observations setting.

Lemma 6.3. If a firm improves upon the characteristic $X_{1}$ and does not know whether the rival is going to improve upon $X_{1}$ or $X_{2}$, its dominant strategy consists of issuing the maximum number of signals independently of the signaling strategy followed by the rival firm. Proof. This result follows from $E[r(\theta)]_{D}>E[r(\theta)]_{C}>E[r(\theta)]_{B}$ and the fact that signaling is a dominant strategy within each subgame composing the technological transition matrix. -

Lemma 6.4. Not-signaling is a strictly dominated strategy when a firm improves upon the characteristic $X_{2}$ and does not know whether the rival is going to improve upon $X_{1}$ or $X_{2}$.

This result follows directly from Lemma 6.3. Note that it holds even if $\left(<E[r(\theta)]_{D}\right)<\left(<E[r(\theta)]_{C}\right)<\left(<E[r(\theta)]_{B}\right)<E[r(\mu)]_{A}$, as is the case in the $X_{2}$-based scenario defined in Table 9. If a firm does not issue a signal, its payoff is either zero or $E[r(\mu)]_{A}$, leading to a strictly lower payoff than the one derived from issuing one, two or three signals on $X_{2}$.

Lemma 6.5. If a firm improves upon the characteristic $X_{2}$ and does not know whether the rival is going to improve upon $X_{1}$ or $X_{2}$, issuing the maximum number of signals does not constitute its dominant strategy. • 
That is, if a firm improves upon the characteristic $X_{2}$ while the rival concentrates on $X_{1}$, then issuing a unique signal provides the highest monopoly payoff within the $X_{2}$-based game. However, if the rival firm also improves upon $X_{2}$, then issuing one signal becomes a strictly dominated strategy. In this regard, if both firms were to hypothetically coordinate within the $X_{2}$-based scenario, they should issue either two signals each (in the two observations setting) or one (in the four observations setting). However, both these strategies are strictly dominated in their corresponding settings. Thus, a mixed strategy equilibrium results when firms must decide whether to improve upon either the first or the second characteristic and the resulting monopolistic markets remain separated. It therefore follows that

Proposition 6.6. The technological transition scenario with two product characteristics to potentially improve upon has a mixed strategy equilibrium consisting of:

(i) improving upon the characteristic $X_{1}$ and issuing the maximum possible number of signals

(ii) improving upon $X_{2}$ and playing a mixed strategy with the potential options resulting from the respective subgames. -

The formal derivation of the mixed strategy equilibrium described in Proposition 6.6 is provided in an online appendix to the current paper. Table 10 and Figure 10 present the equilibrium probabilities obtained in the two observations setting, i.e. within a developing product market.

Similarly, Table 11 and Figure 11 present the equilibrium probabilities obtained in the four observations setting, i.e. in the early stages of market development.

The mixed strategy equilibria obtained in both settings illustrate how the degree of risk aversion of the DMs and their willingness to acquire information have a considerable influence on the signaling strategies followed by the firms.

Table 10. Equilibrium probabilities in the two observations setting

\begin{tabular}{|c|c|c|c|c|}
\hline Risk & $\mathbf{P}\left(\boldsymbol{X}_{\mathbf{1}}\right)$ & $\mathbf{P}(\mathbf{1 S})$ & $\mathbf{P}(\mathbf{2 S})$ & $\mathbf{P}(\mathbf{3 S})$ \\
\hline Neutrality & 0.4995 & 0.5005 & 0 & 0 \\
\hline Aversion & 0.5285 & 0.4227 & 0 & 0.0488 \\
\hline
\end{tabular}

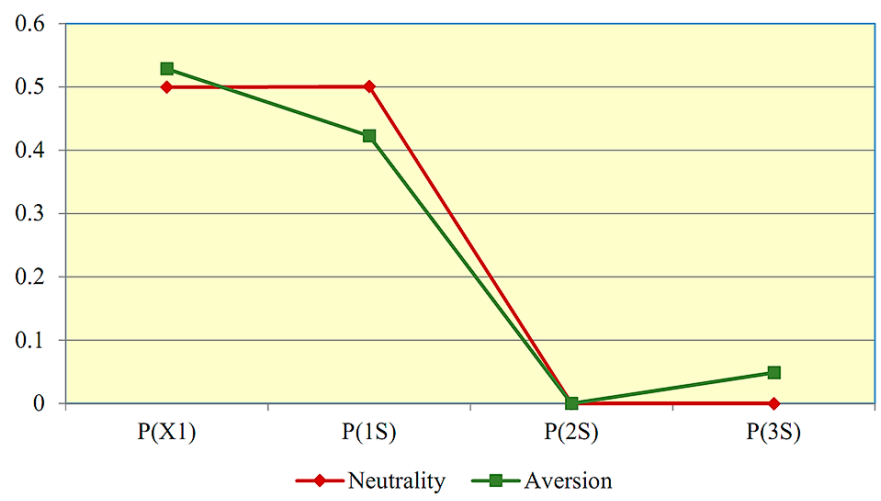

Figure 10. Equilibrium probabilities within a developing product market 
Table 11. Equilibrium probabilities in the four observations setting

\begin{tabular}{|c|c|c|c|c|}
\hline Risk & $\mathbf{P}\left(\boldsymbol{X}_{\mathbf{1}}\right)$ & $\mathbf{P}(\mathbf{1 S})$ & $\mathbf{P}(\mathbf{2 S})$ & $\mathbf{P}(\mathbf{3 S})$ \\
\hline Neutrality & 0.8851 & 0 & 0.0595 & 0.0554 \\
\hline Aversion & 0.9506 & 0 & 0 & 0.0494 \\
\hline
\end{tabular}

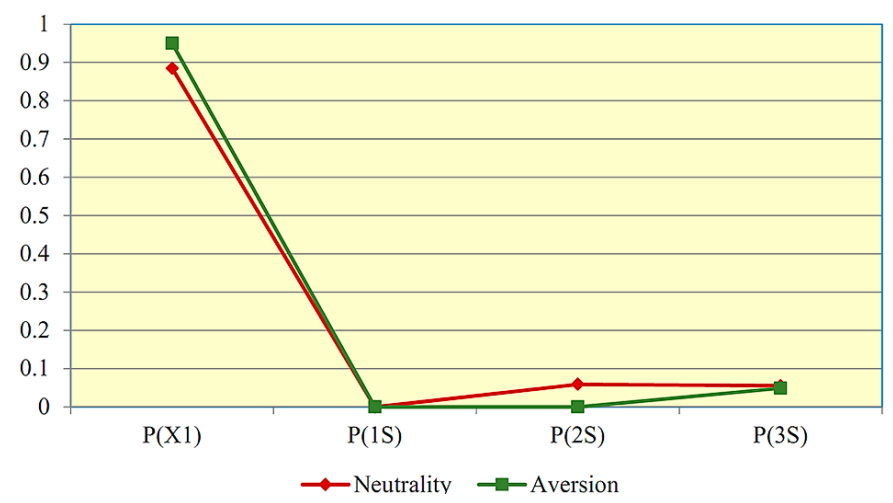

Figure 11. Equilibrium probabilities in the early stages of market development

Consider the fierce competition and subsequent trials taking place between Apple and Samsung regarding the design of their smartphones and tablets in the early stages of market development. Figure 11 illustrates how their efforts were focused at improving the main characteristic of their technological devices while dedicating marginal attention to the secondary characteristic. As the product market developed, substantial efforts were made to improve the operating system (a secondary characteristic at the time) of both devices through sequential upgrades, with Samsung emphasizing their compatibility. Figure 10 illustrates this priority shift, which took place as DMs got used to the technology and less relevant upgrades started to be introduced more frequently.

Note how, as the market develops, risk-averse DMs lead firms to consider full signaling when improving upon $X_{2}$ while risk-neutral DMs do not. This effect is mainly due to the lower difference in payoffs between $E[r(\theta)]_{D}^{x}$ and $E[r(\theta)]_{B}$ under risk aversion, which increases the relative incentives of firms to concentrate on improving upon $X_{2}$, forcing them to be more cautious about the resulting payoffs. The corresponding mixed strategy equilibrium computed under risk-neutrality shows how firms concentrate equal efforts on improving the secondary (though issuing just one signal) and the main characteristic of their products.

Thus, our demand-based equilibrium model provides an analysis of the optimal behavior of firms through the initial stages of market development, with large amounts of potential consumers becoming available in monopolizable niche markets.

Clearly, a shift in market composition would modify the mixed strategy equilibrium obtained. For example, as the smartphone vendors target lower income groups, it may be assumed that the decrease in the price of the product is followed by an increase in risk aversion among potential users. That is, low income DMs tend to be more risk averse than high income ones, Shaw (1996) and Bucciol and Miniaci (2011), which has a direct effect on the set of mixed strategy equilibria obtained. Note also that, in our formal environment, more 
risk averse DMs have lower rejection probabilities when facing technologically improved products.

Finally, note that a firm operating as the sole monopolist within a given technological market has an incentive to improve upon the first characteristic and issue the maximum possible number of signals in all scenarios, independently of the actions taken by any potential competitors. This result provides an alternative demand-based explanation to the Apple's leapfrogging strategy analyzed by Li and Jin (2009) from a supply perspective. In this case, Apple introduced the iPod Nano before newcomers could pose a serious threat within the market developed by the iPod Mini, creating and monopolizing its own technological niche market. Note, however, how the incentives to develop technological improvements disappear when the latter are defined on the second product characteristic.

We conclude this section describing another significant difference between our information acquisition setting and the standard one based on the expected value thresholds. We must however rely on numerical analysis to illustrate the different sets of equilibria generated by the signaling games in both settings. In our setting, issuing three signals constitutes a dominant strategy when considering $X_{1}$, which limits the number of elements composing the set of potential equilibria.

Tables 12 and 13 present the risk neutral payoffs obtained when signals are issued on $X_{1}$ and the expected values of the first and the second characteristic are used as reference thresholds. Note how the dominant pattern generated by the monopolistic payoffs in our setting is eliminated here, i.e. $E[r(\theta)]_{D}<E[r(\theta)]_{C}<E[r(\theta)]_{B}$. This type of pattern is also obtained in the risk averse case, when using the certainty equivalent values as reference thresholds. Consequently, all potential signaling strategies must be considered in both games when defining the corresponding equilibrium.

Thus, the equilibrium structures derived from both settings would differ substantially as a result of the information acquisition behavior of the DMs.

Table 12. Technological transition: two observations, risk-neutral DM, and signals on $X_{1}$ : expected value reference setting

\begin{tabular}{|c|c|c|c|c|c|}
\hline \multicolumn{2}{|c|}{} & \multicolumn{4}{|c|}{ Firm } \\
\cline { 3 - 6 } \multicolumn{2}{|c|}{} & $3 \boldsymbol{s}$ & $\mathbf{2 s}$ & $\mathbf{1 s}$ & $\boldsymbol{n s}$ \\
\hline \multirow{4}{*}{ Rival } & $\boldsymbol{3}$ & $(0.7460,0.7460)$ & $(0.7417,1)$ & $(0.7417,1)$ & $(0.7417,1)$ \\
\cline { 2 - 6 } & $\mathbf{s}$ & $(1,0.7417)$ & $(0.7408,0.7408)$ & $(0.7300,1)$ & $(0.7300,1)$ \\
\cline { 2 - 6 } & $\mathbf{1} \boldsymbol{s}$ & $(1,0.7417)$ & $(1,0.7300)$ & $(0.7363,0.7363)$ & $(0.7188,1)$ \\
\cline { 2 - 6 } & $\boldsymbol{n s}$ & $(1,0.7417)$ & $(1,0.7300)$ & $(1,0.7188)$ & $(0.7500,0.7500)$ \\
\hline
\end{tabular}

Table 13. Technological transition: four observations, risk-neutral DM, and signals on $X_{1}$ : expected value reference setting

\begin{tabular}{|c|c|c|c|c|c|}
\hline & \multicolumn{4}{|c|}{ Firm } \\
\hline & & $3 s$ & $2 s$ & $1 s$ & $n s$ \\
\hline \multirow{4}{*}{ Rival } & $3 s$ & $(0.7751,0.7751)$ & $(0.7417,1)$ & $(0.7417,1)$ & $(0.7417,1)$ \\
\hline & $2 s$ & $(1,0.7417)$ & $(0.7665,0.7665)$ & $(0.7300,1)$ & $(0.7300,1)$ \\
\hline & $1 s$ & $(1,0.7417)$ & $(1,0.7300)$ & $(0.7583,0.7583)$ & $(0.7188,1)$ \\
\hline & $n s$ & $(1,0.7417)$ & $(1,0.7300)$ & $(1,0.7188)$ & $(0.7813,0.7813)$ \\
\hline
\end{tabular}




\section{Managerial implications}

The optimal behavior of firms described by the model is reflected in the events that took place as the market for smartphones and tablets was being developed. Together with the emphasis placed on the design of their products, which constituted the main characteristic among consumers in the early stages of market development, both firms (Apple and Samsung) introduced a considerable number of sequential upgrades on secondary characteristics within relatively short periods of time as the market developed. This dosification in the introduction of technological improvements among secondary characteristics has been repeatedly emphasized by consumers, see Arruda-Filhoa and Lennon (2011).

Thus, both firms focused initially on improving the main characteristic category to its highest available level, which has remained fairly steady ever since. This strategy differs from the sequential doses of improvements introduced on the secondary (at the time) characteristics as the market developed. In this latter case, substantial improvements would have required longer periods of time to be implemented and, more importantly, would have been recognized as such by the consumers, who have repeatedly questioned their significance, see Arruda-Filhoa and Lennon (2011).

The current model is particularly effective during the initials stages of market development, as consumers adapt to a new technological product whose set of characteristics can be repeatedly improved (Dedehayir, Nokelainen \& Mäkinen, 2014). Thus, the current model serves as a complement to the literature on supply-chain design and configuration when different product updates are sequentially introduced and their expected diffusion processes must be considered beforehand (Amini \& Li, 2011; Li et al., 2012; Ji \&d Gunasekaran, 2014).

As the market evolves further, the strategic structure under consideration must account for potential modifications in the preferences of DMs and the emergence of different consumer bases for each firm. In this regard, information on the product characteristics that consumers consider must be improved, as well as their expectations on the degree of these potential improvements (retrievable from the EverythingiCafe and Androidcentral websites), has become widely available not only to firm managers but also to the general public.

Several guidelines regarding the managerial implementation of the current information acquisition and decision structures within a related theoretical environment have been provided by Tavana, Di Caprio \& Santos Arteaga, (2014). In the current setting, in addition to the data that they may privately gather to elicit the preferences, utilities and beliefs of DMs, managers have at their disposal plenty of free widespread and easily accessible information regarding the type of DMs acquiring their products and their relative proportions within the population of potential consumers.

\section{Conclusions}

This study has highlighted the essential role played by the preferences and information acquisition incentives of DMs in the technological product development strategies of firms. This has been done by incorporating the main properties of the TAMs developed by management scholars into a pre-commitment signaling duopolistic framework, where two competing firms must decide the level of technological improvement of the products being introduced. 
The resulting demand-based equilibrium environment allows firms to base their product introduction strategies on the expected information acquisition and choice behavior of DMs arising from the technological modifications introduced in their products.

The current paper has presented a credible noiseless scenario where firms report their real distributions of characteristics and DMs interpret these signals as truthful reports. Immediate extensions of the paper should account for different types of potential strategic market interactions, since DMs do not generally observe the real distributions of characteristics. In other words, a principal may always issue signals so as to manipulate the choice of uninformed but perfectly rational agents. It should be emphasized that preference manipulation may occur even if the information transmitted is fully verifiable by the DM (Di Caprio \& Santos Arteaga, 2011). As a result, the strategic quality of the information transmission process should be considered at the managerial level (Holsapple, 2003), and the organizational one (Gaines, 2003), where the effect of variables such as the reputation of the information sender could be accounted for and studied.

It should be emphasized that MCDM and TAM models do not consider the effects of reputation on the decision process of DMs - and the resulting signaling strategies of firms -, though it can be easily incorporated in our current formal setting. In this regard, patent wars could be studied as a strategic phenomenon whose output is determined by the potential reputation effects on the firms involved. Nam, S., Nam, C. \& Kim (2015) analyzed the main wealth effects of patent litigation in the smartphone industry, focusing particularly on the negative stock returns faced by Asian firms when being sued by Apple. The same type of analysis was performed by Wang, Lin, W.-R., Lin, S.-S. \& Hung (2017), who observed empirically how market leaders experienced lower risks when facing lawsuits regarding patent infringements, while the risk reactions of competitors differed substantially during a patent war.

Finally, among the potential extensions of the current strategic setting, we should highlight the inclusion of copycats and credibility features within the signaling structure of the game. Indeed, a credibility variable can be directly introduced in the information acquisition and decision processes of DMs so as to condition the signaling strategies of firms. Gao, Lim \& Tang (2016) illustrated how the potential entry of a firm producing and selling a copycat product that competes with the incumbent on a duopolistic two-period non-cooperative game would lead the incumbent to decrease its selling price. Similarly, Pun and DeYong (2017) defined a two-period game where a manufacturer had to decide the amount of investment on market expansion advertising whose benefits could end up being shared with a copycat. Their setting considered perfectly informed customers who decided whether or not, when, and which product to buy. These authors found counterintuitive results that could be complemented through our sequential search process, since strategic DMs must still acquire and validate the information observed regarding the product being advertised.

\section{Acknowledgements}

The authors would like to thank the anonymous reviewers and the editor for their insightful comments and suggestions. 


\section{References}

Aggarwal, S., Gupta, A., Govindan, K., Jha, P. C., \& Meidute, I. (2014). Effect of repeat purchase and dynamic market size on diffusion of an innovative technological consumer product in a segmented market. Technological and Economic Development of Economy, 20(1), 97-115. https://doi.org/10.3846/20294913.2014.885914

Aldhaban, F. (2012). Exploring the adoption of smartphone technology: literature review. In Proceedings of PICMET '12: Technology Management for Emerging Technologies, 2758-2770.

Amini, M., \& Li, H. (2011). Supply chain configuration for diffusion of new products: an integrated optimization approach. Omega, 39(3), 313-322. https://doi.org/10.1016/j.omega.2010.07.009

Arruda-Filhoa, E. J. M., Cabusasb, J. A., \& Dholakiab, N. (2010). Social behavior and brand devotion among iPhone innovators. International Journal of Information Management, 30(6), 475-480. https://doi.org/10.1016/j.ijinfomgt.2010.03.003

Arruda-Filhoa, E. J. M., \& Lennon, M. M. (2011). How iPhone innovators changed their consumption in iDay2: hedonic post or brand devotion. International Journal of Information Management, 31(6), 524-532. https://doi.org/10.1016/j.ijinfomgt.2011.04.007

Bohlmann, J. D., Golder, P. N., \& Mitra, D. (2002). Deconstructing the pioneer's advantage: examining vintage effects and consumer valuations of quality and variety. Management Science, 48(9), 11751195. https://doi.org/10.1287/mnsc.48.9.1175.175

Bucciol, A., \& Miniaci, R. (2011). Household portfolios and implicit risk preference. Review of Economics and Statistics, 93(4), 1235-1250. https://doi.org/10.1162/REST_a_00138

Chen, C.-M., \& Ann, B.-Y. (2016). Efficiencies vs. importance-performance analysis for the leading smartphone brands of Apple, Samsung and HTC. Total Quality Management \& Business Excellence, 27(3-4), 227-249. https://doi.org/10.1080/14783363.2014.976937

Cockrill, A. (2012). Does an iPod make you happy? An exploration of the effects of iPod ownership on life satisfaction. Journal of Consumer Behaviour, 11(5), 406-414. https://doi.org/10.1002/cb.1385

Davis, F. D. (1989). Perceived usefulness, perceived ease of use, and user acceptance of information technology. MIS Quarterly, 13(3), 319-340. https://doi.org/10.2307/249008

Dedehayir, O., Nokelainen, T., \& Mäkinen, S. J. (2014). Disruptive innovations in complex product systems industries: a case study. Journal of Engineering and Technology Management, 33, 174-192. https://doi.org/10.1016/j.jengtecman.2014.06.002

Di Caprio, D., \& Santos Arteaga, F. J. (2011). Strategic diffusion of information and preference manipulation. International Journal of Strategic Decision Sciences, 2(2), 1-19. https://doi.org/10.4018/ijsds.2011040101

Di Caprio, D., \& Santos Arteaga, F. J. (2014). Climbing quality ladders and the evolution of technology dynamics: rethinking the role of demand in technological change. International Journal of Operational Research, 20(2), 121-155. https://doi.org/10.1504/IJOR.2014.061770

Di Caprio, D., Santos Arteaga, F. J., \& Tavana, M. (2014). The optimal sequential information acquisition structure: a rational utility-maximizing perspective. Applied Mathematical Modelling, 38(14), 3419-3435. https://doi.org/10.1016/j.apm.2013.12.003

Di Caprio, D., Santos-Arteaga, F. J., \& Tavana, M. (2016). An optimal sequential information acquisition model subject to a heuristic assimilation constraint. Benchmarking: An International Journal, 23(4), 937-982. https://doi.org/10.1108/BIJ-01-2014-0008

Dillon, A., \& Morris, M. (1996). User acceptance of new information technology: theories and models. In M. Williams (Ed.). Annual review of information science and technology (vol. 31, pp. 3-32). Medford NJ: Information Today.

Gaines, B. R. (2003). Organizational knowledge acquisition. In C. W. Holsapple (Ed.). Handbook of knowledge management 1. Knowledge matters (pp. 317-348). Berlin: Springer-Verlag. 
Gao, S. Y., Lim, W. S., \& Tang, C. (2016). The impact of the potential entry of copycats: entry conditions, consumer welfare, and social welfare. Decision Sciences, pp. 1-31.

Geroski, P. A. (2000). Models of technology diffusion. Research Policy, 29(4-5), 603-625. https://doi.org/10.1016/S0048-7333(99)00092-X

Gerpott, T. J., Thomas, S., \& Weicher, M. (2013). Characteristics and mobile internet use intensity of consumers with different types of advanced handsets: an exploratory empirical study of iPhone, Android and other web-enabled mobile users in Germany. Telecommunications Policy, 37(4-5), 357-371. https://doi.org/10.1016/j.telpol.2012.04.009

Gobble, M. M. (2012). Apple scores a win in the smartphone wars. Research-Technology Management, 55(6), 4-5.

Greenleaf, E. A., \& Lehmann, D. R. (1995). Reasons for substantial delay in consumer decision making. The Journal of Consumer Research, 22(2), 186-199. https://doi.org/10.1086/209444

Hameed, M. A., Counsell, S., \& Swift, S. (2012). A conceptual model for the process of IT innovation adoption in organizations. Journal of Engineering and Technology Management, 29(3), 358-390. https://doi.org/10.1016/j.jengtecman.2012.03.007

Holsapple, C. W. (Ed.). (2003). Handbook of knowledge management 2. Knowledge directions. Berlin: Springer-Verlag. https://doi.org/10.1007/978-3-540-24748-7

Hsu, W.-C. J., Tsai, M.-H., \& Tzeng, G.-H. (2017). Exploring the best strategy plan for improving the digital convergence by using a hybrid MADM model. Technological and Economic Development of Economy, 24(1), 164-198. https://doi.org/10.3846/20294913.2016.1205531

Ji, G., \& Gunasekaran, A. (2014). Evolution of innovation and its strategies: from ecological niche models of supply chain clusters. Journal of the Operational Research Society, 65(6), 888-903. https://doi.org/10.1057/jors.2013.136

Kenney, M., \& Pon, B. (2011). Structuring the smartphone industry: is the mobile internet OS platform the key?. Journal of Industry, Competition and Trade, 11(3), 239-261.

https://doi.org/10.1007/s10842-011-0105-6

Kim, S. K., Lee, B. G., Park, B. S., \& Oh, K. S. (2011). The effect of R\&D, technology commercialization capabilities and innovation performance. Technological and Economic Development of Economy, 17(4), 563-578. https://doi.org/10.3846/20294913.2011.603481

Lee, J., \& Le, J. N. (2009). Understanding the product information inference process in electronic wordof-mouth: an objectivity-subjectivity dichotomy perspective. Information \& Management, 46(5), 302-311. https://doi.org/10.1016/j.im.2009.05.004

Li, Y., \& Jin, Y. H. (2009). Racing to market leadership: product launch and upgrade decisions. International Journal of Production Economics, 119(2), 284-297. https://doi.org/10.1016/j.ijpe.2009.03.004

Li, Y. L., Tang, J. F., Chin, K. S., Luo, X. G., Pu, Y., \& Jiang, Y. S. (2012). On integrating multiple type preferences into competitive analyses of customer requirements in product planning. International Journal of Production Economics, 139(1), 168-179. https://doi.org/10.1016/j.ijpe.2012.03.031

Liao, C.-N., Lin, C.-H., \& Fu, Y.-K. (2016). Integrative model for the selection of a new product launch strategy, based on ANP, TOPSIS and MCGP: a case study. Technological and Economic Development of Economy, 22(5), 715-737. https://doi.org/10.3846/20294913.2015.1074951

Lin, C.-Y., Chao, Y.-C., \& Tang, T.-W. (2017). Why not be "smarter"? Examining the factors that influence the behavioral intentions of non-smartphone users. Industrial Management \& Data Systems, 117(1), 32-49. https://doi.org/10.1108/IMDS-07-2015-0319

Malerba, F., Nelson, R., Orsenigo, L., \& Winter, S. (2007). Demand, innovation, and the dynamics of market structure: the role of experimental users and diverse preferences. Journal of Evolutionary Economics, 17(4), 371-399. https://doi.org/10.1007/s00191-007-0060-х 
Marcondes Moraes, G. H. S. (2016). Herd behavior in the use of information technology. IEEE Latin America Transactions, 14(8), 3868-3874. https://doi.org/10.1109/TLA.2016.7786374

Maruping, L. M., Bala, H., Venkatesh, V., \& Brown, S. A. (2017). Going beyond intention: integrating behavioral expectation into the unified theory of acceptance and use of technology. Journal of the Association for Information Science and Technology, 68(3), 623-637. https://doi.org/10.1002/asi.23699

Mas-Colell, A., Whinston, M. D., \& Green, J. R. (1995). Microeconomic theory. New York: Oxford University Press.

Nam, S., Nam, C., \& Kim, S. (2015). The impact of patent litigation on shareholder value in the smartphone industry. Technological Forecasting and Social Change, 95, 182-190. https://doi.org/10.1016/j.techfore.2015.01.015

Nelson, P. (1970). Information and consumer behavior. Journal of Political Economy, 78(2), 311-329. https://doi.org/10.1086/259630

Phan, K., \& Daim, T. (2011). Exploring technology acceptance for mobile services. Journal of Industrial Engineering and Management, 4(2), 339-360. https://doi.org/10.3926/jiem.2011.v4n2.p339-360

Prabhakar Murthy, D. N., Rausand, M., \& Østerås, T. (2008). Product reliability. Specification and performance. Springer-Verlag London.

Pun, H., \& DeYong, G. D. (2017). Competing with copycats when customers are strategic. Manufacturing \& Service Operations Management, 19(3), 403-418. https://doi.org/10.1287/msom.2016.0613

Rogers, E. (2003). Diffusion of innovation (5 $5^{\text {th }}$ ed.). Free Press.

Rosen, S. (1974). Hedonic prices and implicit markets: product differentiation in pure competition. The Journal of Political Economy, 82(1), 34-55. https://doi.org/10.1086/260169

Saaty, T. L. (1980). The analytic hierarchy process. New York: McGraw-Hill.

Samiee, S., Shimp, T. A., \& Sharma, S. (2005). Brand origin recognition accuracy: its antecedents and consumers' cognitive limitations. Journal of International Business Studies, 36(4), 379-397. https://doi.org/10.1057/palgrave.jibs.8400145

Shaw, K. L. (1996). An empirical analysis of risk aversion and income growth. Journal of Labor Economics, 14(4), 626-653. https://doi.org/10.1086/209825

Shin, D.-H. (2017). Conceptualizing and measuring quality of experience of the internet of things: exploring how quality is perceived by users. Information \& Management, 54(8), 998-1011. https://doi.org/10.1016/j.im.2017.02.006

Simon, H. (1955). A behavioral model of rational choice. Quarterly Journal of Economics, 69(1), 99-118. https://doi.org/10.2307/1884852

Sutton, J. (1998). Technology and market structure: theory and history. MIT Press.

Swapana, M., \& Padmavathy, C. (2017). Factors influencing dependency on smartphone and the impact on purchase behaviour: an empirical research. International Journal of E-Business Research, 13(2), 79-92. https://doi.org/10.4018/IJEBR.2017040105

Tavana, M. (2004). A subjective assessment of alternative mission architectures for the human exploration of Mars at NASA using multicriteria decision making. Computers \& Operations Research, 31(7), 1147-1164. https://doi.org/10.1016/S0305-0548(03)00074-1

Tavana, M., Di Caprio, D., \& Santos Arteaga, F. J. (2014). An optimal information acquisition model for competitive advantage in complex multiperspective environments. Applied Mathematics and Computation, 240, 175-199. https://doi.org/10.1016/j.amc.2014.04.074

Tavana, M., Di Caprio, D., \& Santos Arteaga, F. J. (2016a). Modeling sequential information acquisition behavior in rational decision making. Decision Science, 47(4), 720-761.

https://doi.org/10.1111/deci.12193 
Tavana, M., Di Caprio, D., \& Santos Arteaga, F. J. (2016b). Loyal customer bases as innovation disincentives for duopolistic firms using strategic signaling and Bayesian analysis. Annals of Operations Research, 244(2), 647-676. https://doi.org/10.1007/s10479-016-2114-7

Tavana, M., Santos Arteaga, F. J., Di Caprio, D., \& Tierney, K. (2016c). Modeling signal-based decisions in online search environments: a non-recursive forward-looking approach. Information \& Management, 53(2), 207-226. https://doi.org/10.1016/j.im.2015.10.002

The Guardian. (2012). Samsung's tablet "not as cool as iPad". Retrieved from http://www.theguardian. com/technology/2012/jul/09/samsung-apple-cool-ipad-tablet

Tirole, J. (1988). The theory of industrial organization. MIT Press.

Tsai, P.-H., \& Chang, S.-C. (2013). Comparing the Apple iPad and non-Apple camp tablet PCs: a multicriteria decision analysis. Technological and Economic Development of Economy, 19(S1), S256-S284. https://doi.org/10.3846/20294913.2013.881929

Tseng, F. M., Liu, Y. L., \& Wu, H. H. (2014). Market penetration among competitive innovation products: the case of the Smartphone Operating System. Journal of Engineering and Technology Management, 32, 40-59. https://doi.org/10.1016/j.jengtecman.2013.10.002

Ulu, C., \& Smith, J. E. (2009). Uncertainty, information acquisition, and technology adoption. Operations Research, 57(3), 740-752. https://doi.org/10.1287/opre.1080.0611

Venkatesh, V., \& Bala, H. (2008). Technology acceptance model 3 and a research agenda on interventions. Decision Sciences, 39(2), 273-315. https://doi.org/10.1111/j.1540-5915.2008.00192.x

Wakker, P. (1989). Additive representations of preferences. A new foundation of decision analysis. Dordrecht: Kluwer Academic Publishers. https://doi.org/10.1007/978-94-015-7815-8

Wang, Y.-H., Lin, W.-R., Lin, S.-S., \& Hung, J.-C. (2017). How does patent litigation influence dynamic risk for market competitors?. Technological and Economic Development of Economy, 23(5), 780-793. https://doi.org/10.3846/20294913.2015.1074949

Weitzman, M. L. (1994). Monopolistic competition with endogenous specialization. The Review of Economic Studies, 61(1), 45-56. https://doi.org/10.2307/2297876

West, J., \& Mace, M. (2007, June). Entering a mature industry through innovation: Apple's iPhone strategy. In DRUID Summer Conference on Appropriability, Proximity, Routines and Innovation. Copenhagen, CBS, Denmark.

Zemlickienè, V., Mačiulis, A., \& Tvaronavičienè, M. (2017). Factors impacting the commercial potential of technologies: expert approach. Technological and Economic Development of Economy, 23(2), 410427. https://doi.org/10.3846/20294913.2016.1271061 


\section{APPENDIX}

In this appendix, we derive the mixed strategy equilibria arising when firms face either the risk-neutral environment introduced in Tables 2, 3,6 and 7 or the risk-averse one defined by Tables 4, 5, 8 and 9 . Note that the entries of these technological transition matrices have been defined in terms of rejection probabilities. In order to provide additional insight and relate these matrices to the analysis performed in the paper, we will define the mixed strategy equilibrium probabilities in terms of the expected profits derived from the introduction of a technologically superior product. Consequently, we will be assuming that the payoff derived from the DM purchasing a product equals one while the absence of purchase delivers a payoff of zero to the corresponding firm. It should be noted that the results obtained are independent of these payoff choices.

Consider the technological transition Game A.1, with signals on $X_{k}, k=1,2$, defined in expected profit terms that follows directly from those represented numerically in Tables 2 to 9:

\section{Gme A.1}

\begin{tabular}{|c|c|c|c|c|}
\hline & $\boldsymbol{3 s}$ & $\mathbf{2 s}$ & $\mathbf{1 s}$ & $\boldsymbol{n s}$ \\
\hline $\boldsymbol{3 s}$ & $\left(<E[r(\theta)]_{D}\right)$ & $E[r(\theta)]_{D}, 0$ & & \\
\hline $\boldsymbol{2} \boldsymbol{s}$ & $0, E[r(\theta)]_{D}$ & $\left(<E[r(\theta)]_{C}\right)$ & $E[r(\theta)]_{C}, 0$ & \\
\hline $\mathbf{1 s}$ & & $0, E[r(\theta)]_{C}$ & $\left(<E[r(\theta)]_{B}\right)$ & $E[r(\theta)]_{B}, 0$ \\
\hline $\boldsymbol{n s}$ & & & $0, E[r(\theta)]_{B}$ & $E[r(\mu)]_{A}$ \\
\hline
\end{tabular}

As described in Lemma 6.3, when focusing on the $X_{1}$-based matrices, the dominant strategy of a firm consists of issuing the maximum possible number of signals in both the risk-neutral and risk-averse cases. However, when playing the $X_{2}$-based matrices, Lemmas 6.4 and 6.5 imply that a mixed strategy based on all three potential signaling options following from the respective subgames must be defined.

Thus, there are two different sets of probabilities that must be accounted for regarding the potential signaling strategies followed by a given firm. The first subset corresponds to its specialization in improving either the first or the second characteristic and is defined by

$$
\left\{P_{i}\left(X_{1}\right), P_{i}\left(X_{2}\right)\right\}_{i=1,2} \text {. }
$$

The second set refers to the subgames that may be played depending on the number of signals issued, i.e. either three, two or one, when a firm concentrates on the second characteristic

$$
\left\{P_{i}(3 s), P_{i}(2 s), P_{i}(1 s)\right\}_{i=1,2} \text {. }
$$

A mixed strategy equilibrium is therefore defined by a set of probabilities for both firms, $i=1,2$, determining the product to improve upon technologically and the number of signals to issue, i.e. the intensity of the improvement:

$$
\left\{P_{i}^{*}\left(X_{1}\right), P_{i}^{*}\left(X_{2}\right)=P_{i}^{*}(3 s)+P_{i}^{*}(2 s)+P_{i}^{*}(1 s)\right\}_{i=1,2} .
$$


Given Lemma 6.3, the dominant strategy to be played when improving $X_{1}$ consist of issuing three signals, leading to the following expected payoff

$$
P_{i}^{*}\left(X_{1}\right) \cdot\left(<E[r(\theta)]_{D}^{x}\right)+P_{i}^{*}\left(X_{2}\right) \cdot E[r(\theta)]_{D}^{x}
$$

Consider now the expected payoffs derived from issuing either one, two or three signals when improving technologically the second characteristic, i.e. when playing the $X_{2}$-based game

$$
\begin{aligned}
& P_{i}^{*}\left(X_{1}\right) \cdot E[r(\theta)]_{B}+P_{i}^{*}\left(X_{2} \mid 1 s\right) \cdot\left(<E[r(\theta)]_{B}\right)+P_{i}^{*}\left(X_{2} \mid 2 s\right) \cdot 0+P_{i}^{*}\left(X_{2} \mid 3 s\right) \cdot 0 \\
& P_{i}^{*}\left(X_{1}\right) \cdot E[r(\theta)]_{C}+P_{i}^{*}\left(X_{2} \mid 1 s\right) \cdot E[r(\theta)]_{C}+P_{i}^{*}\left(X_{2} \mid 2 s\right) \cdot\left(<E[r(\theta)]_{C}\right)+P_{i}^{*}\left(X_{2} \mid 3 s\right) \cdot 0 \\
& P_{i}^{*}\left(X_{1}\right) \cdot E[r(\theta)]_{D}+P_{i}^{*}\left(X_{2} \mid 1 s\right) \cdot E[r(\theta)]_{D}+P_{i}^{*}\left(X_{2} \mid 2 s\right) \cdot E[r(\theta)]_{D}+ \\
& P_{i}^{*}\left(X_{2} \mid 3 s\right) \cdot\left(<E[r(\theta)]_{D}\right) .
\end{aligned}
$$

The mixed strategy equilibrium is defined by the solutions of the following system of equations:

$$
\begin{aligned}
& \left(1-P_{i}^{*}(3 s)-P_{i}^{*}(2 s)-P_{i}^{*}(1 s)\right) \cdot\left(<E[r(\theta)]_{D}^{x}\right)+\left(P_{i}^{*}(3 s)+P_{i}^{*}(2 s)+P_{i}^{*}(1 s)\right) \cdot E[r(\theta)]_{D}^{x}= \\
& \left(1-P_{i}^{*}(3 s)-P_{i}^{*}(2 s)-P_{i}^{*}(1 s)\right) \cdot E[r(\theta)]_{B}+P_{i}^{*}\left(X_{2} \mid 1 s\right) \cdot\left(<E[r(\theta)]_{B}\right) ; \\
& \left(1-P_{i}^{*}(3 s)-P_{i}^{*}(2 s)-P_{i}^{*}(1 s)\right) \cdot E[r(\theta)]_{B}+P_{i}^{*}\left(X_{2} \mid 1 s\right) \cdot\left(<E[r(\theta)]_{B}\right)= \\
& \left(1-P_{i}^{*}(3 s)-P_{i}^{*}(2 s)-P_{i}^{*}(1 s)\right) \cdot E[r(\theta)]_{C}+P_{i}^{*}\left(X_{2} \mid 1 s\right) \cdot E[r(\theta)]_{C}+ \\
& \left.P_{i}^{*}\left(X_{2} \mid 2 s\right)\right) \cdot\left(<E[r(\theta)]_{C}\right) ; \\
& \left(1-P_{i}^{*}(3 s)-P_{i}^{*}(2 s)-P_{i}^{*}(1 s)\right) \cdot E[r(\theta)]_{C}+P_{i}^{*}\left(X_{2} \mid 1 s\right) \cdot E[r(\theta)]_{C}+ \\
& \left.P_{i}^{*}\left(X_{2} \mid 2 s\right)\right) \cdot\left(<E[r(\theta)]_{C}\right)=\left(1-P_{i}^{*}(3 s)-P_{i}^{*}(2 s)-P_{i}^{*}(1 s)\right) \cdot E[r(\theta)]_{D}+ \\
& \left.P_{i}^{*}\left(X_{2} \mid 1 s\right) \cdot E[r(\theta)]_{D}+P_{i}^{*}\left(X_{2} \mid 2 s\right) \cdot E[r(\theta)]_{D}+P_{i}^{*}\left(X_{2} \mid 3 s\right)\right) \cdot\left(<E[r(\theta)]_{D}\right) .
\end{aligned}
$$

After some algebra, the resulting probabilities are given by

$$
\begin{aligned}
& P_{i}^{*}(3 s)=\frac{E[r(\theta)]_{C}+\gamma\left(<E[r(\theta)]_{C}\right)-E[r(\theta)]_{C}-E[r(\theta)]_{D}}{\left(<E[r(\theta)]_{D}\right)-E[r(\theta)]_{D}+E[r(\theta)]_{C}-\delta} ; \\
& P_{i}^{*}(2 s)=\gamma+\frac{P_{i}^{*}(3 s)\left(\beta-E[r(\theta)]_{B}+E[r(\theta)]_{C}\right)}{\left(<E[r(\theta)]_{C}\right)-E[r(\theta)]_{C}+E[r(\theta)]_{B}-\beta} ; \\
& P_{i}^{*}(1 s)=\alpha+\frac{\left(P_{i}^{*}(3 s)+P_{i}^{*}(2 s)\right)\left(E[r(\theta)]_{D}^{x}+E[r(\theta)]_{B}-\left(<E[r(\theta)]_{D}^{x}\right)\right.}{\left(<E[r(\theta)]_{B}\right)-E[r(\theta)]_{B}+\left(<E[r(\theta)]_{D}^{x}\right)-E[r(\theta)]_{D}^{x}}
\end{aligned}
$$

with

$$
\begin{aligned}
& \alpha=\frac{\left.\left(<E[r(\theta)]_{D}^{x}\right)\right)-E[r(\theta)]_{B}}{\left(<E[r(\theta)]_{B}\right)-E[r(\theta)]_{B}+\left(<E[r(\theta)]_{D}^{x}\right)-E[r(\theta)]_{D}^{x}} ; \\
& \beta=\frac{\left(E[r(\theta)]_{D}^{x}+E[r(\theta)]_{B}-\left(<E[r(\theta)]_{D}^{x}\right)\right)\left(\left(<E[r(\theta)]_{B}\right)-E[r(\theta)]_{B}\right)}{\left(<E[r(\theta)]_{B}\right)-E[r(\theta)]_{B}+\left(<E[r(\theta)]_{D}^{x}\right)-E[r(\theta)]_{D}^{x}} ; \\
& \gamma=\frac{E[r(\theta)]_{B}+\alpha\left(\left(<E[r(\theta)]_{B}\right)-E[r(\theta)]_{B}\right)-E[r(\theta)]_{C}}{\left(<E[r(\theta)]_{C}\right)-E[r(\theta)]_{C}+E[r(\theta)]_{B}-\beta} ;
\end{aligned}
$$




$$
\delta=\frac{\left(\beta-E[r(\theta)]_{B}+E[r(\theta)]_{C}\right)\left(\left(<E[r(\theta)]_{C}\right)-E[r(\theta)]_{C}\right)}{\left(<E[r(\theta)]_{C}\right)-E[r(\theta)]_{C}+E[r(\theta)]_{B}-\beta} .
$$

The numerical results obtained when accounting for the expected profits of firms differ between both risk-based scenarios. For example, consider the risk-averse case described in Tables 4 and 5, which leads to the following mixed strategy equilibrium results

$$
\begin{aligned}
& P_{i}^{*}(3 s)=0.1358 ; P_{i}^{*}(2 s)=-0.0444 ; P_{i}^{*}(1 s)=0.3514 ; \\
& \alpha=0.5045 ; \beta=0.3298 ; \gamma=-0.7039 ; \delta=-0.6308 .
\end{aligned}
$$

Clearly, issuing two signals constitutes a dominated strategy, which, after being eliminated from the set of potential $X_{2}$-based strategies, leads to

$$
\begin{aligned}
& P_{i}^{*}(3 s)=0.0488 ; P_{i}^{*}(1 s)=0.4227 ; P_{i}^{*}\left(X_{1}\right)=0.5285 ; \\
& \alpha=0.5045 ; \beta=0.3298 .
\end{aligned}
$$

Similarly, Tables 2 and 3 lead to the following mixed strategy equilibrium results within a risk-neutral environment

$$
\begin{aligned}
& P_{i}^{*}(3 s)=0.1177 ; P_{i}^{*}(2 s)=-0.1574 ; P_{i}^{*}(1 s)=0.5717 \\
& \alpha=0.5005 ; \beta=0.2524 ; \gamma=-0.4425 ; \delta=-0.2446 .
\end{aligned}
$$

As in the risk-averse case, issuing two signals constitutes a dominated strategy, which, after being removed, leads to

$$
\begin{aligned}
& P_{i}^{*}(3 s)=-0.1452 ; P_{i}^{*}(1 s)=0.7608 ; \\
& \alpha=0.5005 ; \beta=0.2524 .
\end{aligned}
$$

Thus, in the current numerical setting, the expected payoffs obtained within the riskneutral scenario prevent the DM also from issuing three signals, leading to the following mixed strategy equilibrium

$$
P_{i}^{*}(1 s)=0.5005 ; P_{i}^{*}\left(X_{1}\right)=0.4995 \text {. }
$$

